\title{
Interactive coupling of regional atmosphere with biosphere in the new generation regional climate system model REMO-iMOVE
}

\author{
C. Wilhelm ${ }^{1,2, *}$, D. Rechid ${ }^{1,2}$, and D. Jacob ${ }^{1,2}$ \\ ${ }^{1}$ Max Planck Institute for Meteorology, Bundesstrasse 56, 20146 Hamburg, Germany \\ ${ }^{2}$ Climate Service Center (CSC), Chilehaus, Fischertwiete 1, 20095 Hamburg, Germany \\ *now in private sector
}

Correspondence to: C. Wilhelm (christof.wilhelm@zmaw.de)

Received: 17 March 2013 - Published in Geosci. Model Dev. Discuss.: 31 May 2013

Revised: 11 April 2014 - Accepted: 20 April 2014 - Published: 6 June 2014

\begin{abstract}
The main objective of this study is the coupling of the regional climate model REMO with a new land surface scheme including dynamic vegetation phenology, and the evaluation of the new model version called REMO with interactive MOsaic-based VEgetation: REMO-iMOVE.

First, we focus on the documentation of the technical aspects of the new model constituents and the coupling mechanism. The representation of vegetation in iMOVE is based on plant functional types (PFTs). Their geographical distribution is prescribed to the model which can be derived from different land surface data sets. Here, the PFT distribution is derived from the GLOBCOVER 2000 data set which is available on $1 \mathrm{~km} \times 1 \mathrm{~km}$ horizontal resolution. Plant physiological processes like photosynthesis, respiration and transpiration are incorporated into the model. The vegetation modules are fully coupled to atmosphere and soil. In this way, plant physiological activity is directly driven by atmospheric and soil conditions at the model time step (two minutes to some seconds). In turn, the vegetation processes and properties influence the exchange of substances, energy and momentum between land and atmosphere. With the new coupled regional model system, dynamic feedbacks between vegetation, soil and atmosphere are represented at regional to local scale.

In the evaluation part, we compare simulation results of REMO-iMOVE and of the reference version REMO2009 to multiple observation data sets of temperature, precipitation, latent heat flux, leaf area index and net primary production, in order to investigate the sensitivity of the regional model to the new land surface scheme and to evaluate the performance of both model versions. Simulations for the regional model domain Europe on a horizontal resolution of $0.44^{\circ}$ had
\end{abstract}

been carried out for the time period 1995-2005, forced with ECMWF ERA-Interim reanalyses data as lateral boundary conditions.

REMO-iMOVE is able to simulate the European climate with the same quality as the parent model REMO2009. Differences in near-surface climate parameters can be restricted to some regions and are mainly related to the new representation of vegetation phenology. The seasonal and interannual variations in growth and senescence of vegetation are captured by the model. The net primary productivity lies in the range of observed values for most European regions. This study reveals the need for implementing vertical soil water dynamics in order to differentiate the access of plants to water due to different rooting depths. This gets especially important if the model will be used in dynamic vegetation studies.

\section{Introduction}

Regional climate change information can be derived by downscaling simulations of general circulation models (GCMs) with regional climate models (RCMs). The spatial resolutions of GCM simulations within the frame of the Coupled Model Intercomparison Project Phase 5 (CMIP5) are in the range of $4^{\circ}$ to $0.5^{\circ}$ (Taylor et al., 2004), but the standard resolution for long-term climate projections is in most cases coarser than $1^{\circ}$. This coarse resolution is not able to sufficiently represent local-scale phenomena like extreme events, circulation characteristics due to orographic effects, structured coast lines or interlaced land use. RCMs have been 
developed to overcome the mentioned effects of scale and to gain more insight into the regional aspects of climate change (Giorgi, 2006). In the past years, RCMs have progressed from pure atmosphere models to climate system models, by coupling with regional ocean and vegetation models. This enables the RCMs to represent biogeophysical, biogeochemical and biogeographical aspects, like carbon cycle or land use practices, in high spatial detail.

A key challenge related to this is the refined representation of surface heterogeneity not only in geographical terms but also in a process-based manner. On the one hand, this will lead to the detailed process description of different surface types and the ability to model short-term surface-atmosphere feedback. On the other hand, long-term phenomena like the carbon cycle or climatic induced land use change can be studied due to the introduction of new processes and variables.

A number of studies reveal that the land surface representation in climate models substantially influences the quality of the simulated climate. A change in the model land surface scheme, which parameterizes the physical processes at the Earth's surface, will lead to differences in the exchange between land surface and atmosphere due to modifications in heat, moisture and momentum fluxes. Avissar and Pielke (1991) show in their early study that mesoscale atmospheric circulation could be influenced by the representation of stomatal conductance because of the important control of the Bowen ratio. Lu et al. (2001), Steiner et al. (2009) and Davin et al. (2011) clearly showed that modifications in model land surface schemes alter the modelled climate.

In the early surface models the annual phenology of vegetation was static. The annual course was shaped like a sine curve, with the peak in summer. This representation lacks the influence of interannual variations in temperature and precipitation on vegetation phenology. In sophisticated interactive land surface schemes the phenology is not static but is able to react directly to the simulated weather and climate conditions.

The aim of this study is to describe and evaluate the coupling of the regional climate model REMO to a vegetation model, which interactively responds to atmospheric and soil moisture conditions. The land surface scheme used is the vegetation model of the Max Planck Institute Earth System Model MPI-ESM (Atmosphere: ECHAM6 (Stevens et al., 2013), Ocean: MPI-OM (Marsland et al., 2003), Land: JSBACH (Reick et al., 2013; Brovkin et al., 2013; Roeckner et al., 2003)). The coupling of REMO and parts of JSBACH introduces an interactive vegetation representation into the regional climate model. It brings in more complex parameterizations of vegetative processes, since the vegetation model includes a process-based representation of evapotranspiration as it resolves explicitly plant photosynthesis and its control on stomatal conductance. The new model version is called REMO-iMOVE: REMO with interactive MOsaicbased VEgetation.
Here, we investigate how the modelled vegetation processes in JSBACH are able to react to the conditions in atmosphere and soil simulated by REMO, and how they feedback to the simulated near-surface climate. Further, we analyse the new quantity of net primary productivity of plants and how they relate to measured rates.

First, we introduce the coupled model system REMOiMOVE. Then, we describe our model experiments, observational data sets and our evaluation method for the European model domain. The evaluation results are presented in detail, demonstrating the capabilities of the new model version REMO-iMOVE and its influence on simulated climate characteristics in Europe. The main results are discussed in a summary section, and finally, we draw our conclusions.

\section{Methods}

\subsection{Model description}

\subsubsection{REMO}

The regional climate model REMO was developed at the Max Planck Institute for Meteorology in Hamburg (Jacob and Podzun, 1997; Jacob, 2001) and is based on parts of the German Weather Service EM-DM model (Majewski, 1991) and the physical parameterizations of the global climate model ECHAM4 (Roeckner et al., 2000). It is under constant development, to keep the model up to date with the latest advancements in climate science. The model constituents are described in various literature (e.g. Pfeiffer, 2006; Kotlarski, 2007; Teichmann, 2010).

As this work is discussing the influence of extending REMO by implementing a new interactive surface scheme, we first describe the currently used surface scheme of REMO in the following.

REMO in the version used here (REMO2009) incorporates a spatially static land surface representation. Physical surface characteristics are defined by soil texture types based on FAO data (Zobler, 1986), by a global data set of vegetation parameters called LSPII (Hagemann et al., 1999; Hagemann, 2002) and a horizontal distribution of major ecosystem types (Olson, 1994). The derivation of snow-free surface albedo from MODIS satellite data is described in Rechid et al. (2009). The geographic distribution of vegetation types and its phenology is prescribed and static throughout the whole simulation Rechid and Jacob (2006).

The hydrological properties of the soil are derived from a relatively coarse source and comprise a simple bucket soil water scheme (e.g. described in Kotlarski, 2007). The soil water amount is filled in a single soil moisture reservoir by precipitation and snowmelt, and depleted by bare soil evaporation from the upper $10 \mathrm{~cm}$ at most. From below, the water can only evaporate by transpiration. The maximum amount of plant-available water is derived from soil substrate and 
plant root depth (Hagemann, 2002). If the soil moisture content reaches saturation, surface runoff occurs. The lateral movement of water is not explicitly modelled. Soil temperatures are calculated from diffusion equations solved in five discrete layers with zero heat flux at the bottom (10 $\mathrm{m}$ depth) according to the scheme of Warrilow et al. (2007).

\subsubsection{REMO-iMOVE}

GCMs have been interactively coupled to vegetation models in order to represent dynamic interactions of vegetation and climate. At the Max Planck Institute for Meteorology the dynamic land surface scheme JSBACH was developed for the GCM ECHAM6, to enhance the capabilities of the GCM towards an Earth System Model (ESM). JSBACH has an advantage compared to models of the LPJ family (Sitch et al., 2003) and other state-of-the-art surface schemes, because it is able to exchange surface fluxes on a model time step basis (approx. $10 \mathrm{~min}$ for GCMs, approx. $2 \mathrm{~min}$ to $2 \mathrm{~s}$ for $\mathrm{RCMs})$. This enables JSBACH to simulate the daily cycle of surface atmosphere interactions. This was a main reason to use JSBACH and to couple it to REMO. A further advantage of JSBACH is the coding similarity to REMO. The physical parameterizations of REMO are based on an older ECHAM version, and the technical coding aspects were beneficial for the development.

The coupled version REMO-iMOVE received all biophysical parameterizations for vegetation modelling of JSBACH, except the dynamic vegetation scheme and the carbon pool parameterization. Nevertheless, land-use change studies can be tackled by providing pre-compiled plant functional type (PFT) distributions to the model every favoured time step. In the following we explain the parts which were implemented into REMO, as well as the coupling methodology.

One of the most distinct advancements of REMO-iMOVE is the introduction of the concept of PFTs. The concept of PFTs consists in the aggregation of various species in use of comparable biophysical characterization and functional traits. Due to this aggregation we are able to handle a small but representative selection of comparable functionality, coexisting in one model grid cell. This concept implicates a mosaic representation of surface vegetation on the biome scale, which allows the explicit representation of up to 16 PFTs within a single grid cell. The 16 PFT classes are differentiated by their major biogeophysical peculiarities and traits (see Table 1).

We base the horizontal distribution of PFT classes on the GLOBCOVER 2000 data set (GLC2000), which is available on $1 \mathrm{~km} \times 1 \mathrm{~km}$ horizontal resolution (Bartholome and Belward, 2005). The classification of GLC2000 contains not only classes which can closely be mapped into PFTs (e.g. needleleaf trees), but also contains mixed vegetation classes (e.g. mixtures of trees and shrubs), which need a further separation into PFTs.
Table 1. Plant functional types incorporated in the model.

\begin{aligned} & \hline 1 Tropical broadleaf evergreen trees \\ & 2 Tropical deciduous trees \\ & 3 Temperate broadleaf evergreen \\ & 4 Temperate deciduous trees \\ & 5 Evergreen coniferous trees \\ & 6 Deciduous coniferous trees \\ & 7 Coniferous shrubs \\ & 8 Deciduous shrubs \\ & 9 C3 grass \\ & 10 C4 grass \\ & 11 Tundra \\ & 12 Swamp \\ & 13 C3 crops \\ & 14 C4 crops \\ & 15 Urban \\ & 15 Bare land \\ & \hline\end{aligned}

On the basis of the fact that vegetation cover is closely connected to climatic regimes (Schultz, 2002), we can connect the vegetation cover information of GLC2000 to the ecosystem classification of Holdridge (1964). With these two information sources an allocation of the mixed GLC2000 classes into PFTs is possible.

The ecosystem classification of Holdridge uses the parameter biotemperature, which is computed according to Eq. (1). Another parameter used is the annual amount of precipitation:

Biotemperature $=\left[\sum_{i=1}^{12}\right.$ monthly_mean_temp $\left.(i)\right] / 12$.

Biotemperature and precipitation were computed using the climatological mean values of CRU3 gridded observation data from 1970 to 2000 (Mitchell and Jones, 2005). The resulting ecosystem type classification based on Holdridge is shown in Table 2.

For each class of the GLC2000 data set we can derive a matrix, based on the ecosystem classes in Table 2, to allocate the mixed vegetation types into PFTs according to the prevailing climate conditions at the grid box location. Table 3 gives an example on how a GLC2000 class "mosaic vegetation" (grassland/shrubland/forest (50$70 \%) /$ cropland $(20-50 \%)$ ) is allocated to PFTs. In a wet forest climate type for example (annual precipitation sum of $1000-2000 \mathrm{~mm} / \mathrm{biotemperature} \mathrm{of} 6-12^{\circ} \mathrm{C}$ ), the surface cover of the GLC2000 class would be split into $40 \%$ of PFT 13 (C3 cropland), $25 \%$ of PFT 4 (deciduous trees), $25 \%$ of PFT 5 (evergreen coniferous) and $10 \%$ PFT 13 or $14(\mathrm{C} 3 / \mathrm{C} 4$ grass).

All the allocation tables to translate GLC2000 classes into PFTs are developed under consideration of suitable vegetation cover of the given climatic region taken from various literature and can be received upon request, but are not considered essential for the understanding at this point. 
Table 2. Ecosystem classification following Holdridge (1964).

\begin{tabular}{|c|c|c|c|c|c|c|}
\hline \multirow[t]{2}{*}{ Biotemp $\left[{ }^{\circ} \mathrm{C}\right]$} & \multicolumn{6}{|c|}{ Precipitation [mm] } \\
\hline & $<125$ & 125 to $<250$ & 250 to $<500$ & 500 to $<1000$ & 1000 to $<2000$ & $>2000$ \\
\hline$<3$ & dry tundra & moist tundra & wet tundra & rain tundra & - & - \\
\hline 3 to $<6$ & desert & dry shrub & moist forest & wet forest & rainforest & - \\
\hline 6 to $<12$ & desert & desert shrub & steppe & moist forest & wet forest & rainforest \\
\hline 12 to $<24$ & desert & desert shrub & $\begin{array}{l}\text { thorn steppe/ } \\
\text { woodland }\end{array}$ & dry forest & moist forest & $\begin{array}{l}\text { wet forest/ } \\
\text { rainforest }\end{array}$ \\
\hline$>24$ & desert & desert shrub & $\begin{array}{l}\text { thorn steppe/ } \\
\text { woodland }\end{array}$ & $\begin{array}{l}\text { very dry } \\
\text { forest }\end{array}$ & dry forest & $\begin{array}{l}\text { moist, wet,rain } \\
\text { forest }\end{array}$ \\
\hline
\end{tabular}

Surface radiation fluxes are determined by the surface albedo. Therefore the albedo representation of the surface plays an important role in climate models. In REMO-iMOVE the total grid cell albedo for the land part is composed of the albedo of vegetation, bare soil and snow and is computed at each model time step. Vegetation albedo is fixed for each PFT. Bare soil albedo is determined by combining the distribution of soil types (Harmonized World Soil Database (FAO/IIASA/ISRIC/ISSCAC/JRC, 2009) with satellite-derived albedo information for soil types in their dry state (Tsvetsinskaya et al., 2011). Albedo characteristics of soils, which are not present in the study of Tsvetsinskaya et al. (2011) were taken from Bonan (2002). To get a more realistic soil albedo, the raw soil albedo values $\left(\alpha_{\text {soil }}\right)$ are combined with a value for litter albedo $\left(\alpha_{\text {litter }}=\right.$ constant $\left.=0.12\right)$, by using a function depending on the PFT types which are present in the grid cell in order to represent the influence of litter on soil albedo ( $\left.\alpha_{\text {soil+litter-wetted }}\right)$. This method is a workaround because the model does not incorporate carbon pools. Therefore it is not known how fast the litter is decomposed and how much litter is accumulated. Litter decomposition is dependent on climate and soil microbiological characteristics. So far we tried to represent the litter accumulation and its influence on soil albedo based on very simple assumptions. Offline tests show that the effect of this feature is nearly negligible for European conditions shown in this study. The bare soil part, where the effect is visible, is very sparse in vegetated grid cells. In regions where vegetation is not present, also the soil darkening due to litter is zero and only the soil albedo is visible which is derived by satellite measurements. In winter, when the bare soil part is visible in most PFTs, distinct changes are seen due to snow-masking effects.

Soil moisture also has a large influence on the albedo of soils. Peterson et al. (1979) show a linear correlation between albedo decrease with soil moisture. They also state: "the lighter the soil, the greater the loss in reflectance". Muller and Decamps (2001) also found a slight linear relationship of the albedo decrease due to wetting as well as a spread in the reflectance behaviour due to different soil textures. In REMO-iMOVE we use a negative exponential relationship between increasing soil moisture and albedo decrease. Offline tests showed that the model-inherent soil water bucket scheme better fits, if this negative exponential relationship is used. This finding needs to be revised, if the model will be advanced by a multi-layer soil moisture representation. The ratio of the actual soil moisture $\mathrm{WS}_{\text {act }}$ and the soil moisture content at field capacity $\mathrm{WS}_{\text {fcap }}$ scales the relationship:

$\alpha_{\text {soil+litter-wetted }}=\alpha_{\text {soil+litter }} \times \exp -0.1 \frac{\mathrm{WS}_{\mathrm{act}}}{\mathrm{WS}_{\mathrm{fcap}}}$.

We assume that above field capacity the soil is darkest, even when wetted further. The lower limit of the soil moisture in this context is given by the permanent wilting point, where we assume that the soil looks dry and therefore is brightest. Here $\alpha_{\text {soil+litter }}$ is used.

The field capacity and wilting point percentage values referred to in the paragraph above are related to the maximum water-holding capacity of the soil volume of a grid box. This maximum water-holding capacity is determined by the soil substrate. The amount of water that is available for plants is dependent on their root characteristics. In REMO as well as in REMO-iMOVE the parameterization described in Hagemann (2002) is used for determining the water-holding capacity of a grid box from soil substrate and vegetation root characteristics.

From the radiation interaction with the soil and vegetation due to reflectance issues, we come to the radiation interaction within the plant canopy, plant productivity and stomatal control. All these parts are taken from the BETHY model (Knorr, 1998) which is a part of JSBACH. BETHY models the radiation interaction with the canopy, photosynthesis, dark respiration and stomatal conduction.

The radiation interaction within the canopy is modelled by the two-stream approximation proposed by Dickinson (1983) and Sellers (1985). In this theory, it is assumed that the distribution of scatterers in the canopy is completely homogeneous, so that the radiation distribution within the canopy is horizontally invariant. The product of this routine is the fraction of photosynthetically active radiation absorbed by the plants in the grid box (fAPAR). Having fAPAR modelled, the photosynthetic rate and dark respiration is computed using 
the amount of soil water, temperature, atmospheric pressure, and the PFT-specific values for leaf area index (LAI), electron transport capacity and carboxylation rate, as well as the atmospheric $\mathrm{CO}_{2}$ concentration. The computation of the photosynthetic rate follows the standard approach used in vegetation modelling, which is the model of Farquhar et al. (1980) for species characterized by the $\mathrm{C} 3$ photosynthetic pathway and the model of Collatz et al. (1992) for species using the C4 photosynthetic pathway. The photosynthesis rate determines the amount of plant transpiration based on the stomata resistance of the vegetation. The parameterization of stomatal control follows a model called BETHY described in Knorr (1998).

The net primary productivity of the vegetation cover in a model grid cell is computed by subtracting the dark respiration from the photosynthesis rate for each PFT fraction.

The following explanation of the interactive phenological scheme of JSBACH was acquired by personal communication between the authors and C. H. Reick, T. Raddatz and R. Schnur of the Max Planck Institute for Meteorology, Hamburg, in the years 2010 and 2011.

The interactive phenological scheme is driven by the atmospheric forcing and the soil hydrological state. It is consistent to the formulation of the LPJ philosophy which follows a general logistic growth approach in the form

$\frac{\mathrm{d} \Lambda}{\mathrm{d} t}=k \Lambda\left(1-\frac{\Lambda}{\Lambda_{\max }}\right)-p \Lambda$

with $\Lambda$ : LAI, $\Lambda_{\max }$ : max. LAI, $k$ : growth rate, $p$ : shedding rate.

Four different phenological characteristics are captured by this approach: raingreen, grasses, crops and summergreen. The fifth phenology type is the evergreen type which always assumes the maximum LAI for the PFT.

The raingreen phenology depends only on the plantavailable water. The PFTs start to increase their LAI value (start to grow), if the plant-available water exceeds the permanent wilting point level. If the plant-available water is above the wilting point level in later time steps and the daybefore productivity is positive, raingreen plants grow further at the logistic growth rate. If the water level drops below wilting point, raingreen PFTs die back also at the logistic rate with $p>k$.

The phenology for grasses is dependent on the plantavailable water, as well as on a temperature threshold. If the plant-available water exceeds the wilting point and the temperature is above $5^{\circ} \mathrm{C}$, the grass PFTs start to grow. Grass PFTs grow further, at the logistic growth rate $(k>p)$ if the day-before net primary production (NPP) rate is positive, plant-available water is above wilting point and the temperature threshold is exceeded. If the day-before NPP rate is negative but water and temperature are fine, grasses do not grow further, but slightly reduce LAI $(p>k)$. The LAI of grass PFTs is reduced if either water or temperature are below the mentioned threshold.
The crop phenology is modelled like the grass phenology with the supplementary that the temperature needed for growth has to be larger than $10^{\circ} \mathrm{C}$. This prevents crops from starting to grow early in spring. The growth rate $k$ for crops depends on the day-before NPP rate:

$k=q \times \mathrm{NPP}_{+} \times \mathrm{SLA}$,

with $q$ : 0.8, SLA: $0.45, \mathrm{NPP}_{+}$: NPP for NPP $>0$.

Crops are harvested and the LAI is set to a minimum value of 0.1 when the heat sum threshold is met. The heat sum specifies the sum of daily mean temperature exceeding $6^{\circ} \mathrm{C}$. The heat sum begins counting on the first day of growth. The exceeding temperature is only summed up if the day before NPP rate was positive. This concept ensures that in warmer climates crops will be harvested earlier, if enough water is present.

The summergreen phenology depends only on soil and air temperatures and can be subdivided into three phases:

- growth phase (spring), characterized by non-zero $k$ and $q=0$,

- vegetative phase (summer), when growth is zero and leaf shedding is small,

- rest phase (autumn and winter), with rapid leaf shedding, growth zero.

The most important points in time the model has to capture are the date when growth starts (spring event) and the date when plant rest begins (autumn event). The beginning of the vegetative phase is modelled by heat summation like in the crop phenology. The spring event is determined following the model of Murray et al. (1989) and depends on the magnitude of daily mean temperatures since the autumn event. The autumn event is triggered by the soil and air temperatures. If the soil temperature falls below a threshold of $10^{\circ} \mathrm{C}$ and the daily mean air temperature is below the soil temperature, the rest phase begins.

An important improvement in REMO-iMOVE is the parameterization of bare soil evaporation. In REMO, bare soil evaporation is allowed only if the soil water content exceeds $90 \%$ of the maximum bucket fill (WS $\mathrm{Wax}_{\max }$ ). REMO-iMOVE admits bare soil evaporation also if the soil water content is below the $90 \%$ threshold, and couples the resistance against evaporation from the bare ground $\left(\eta_{\text {bare }}\right)$ to the bucket fill and the area of bare soil in the grid cell. The values of $\eta_{\text {bare }}$ follow a model-inherent logic: the higher the values, the less water is evaporated from bare soil.

The method built into REMO-iMOVE allows bare soil evaporation at maximum rate $\left(\eta_{\text {bare }}=20 \%\right)$, if water is available in the soil ( $>35 \%$ of $\mathrm{WS}_{\max }$ ) and if the vegetation cover is minimal ( $\mathrm{LAI}<1$ ). Here the shadowing of the soil due to plants is only fractional. If bare soil shadowing by plants is abundant ( $\mathrm{LAI} \geq 1$ ), the resistance against bare soil evaporation will take a higher value $\left(\eta_{\text {bare }}=45 \%\right)$ if enough 


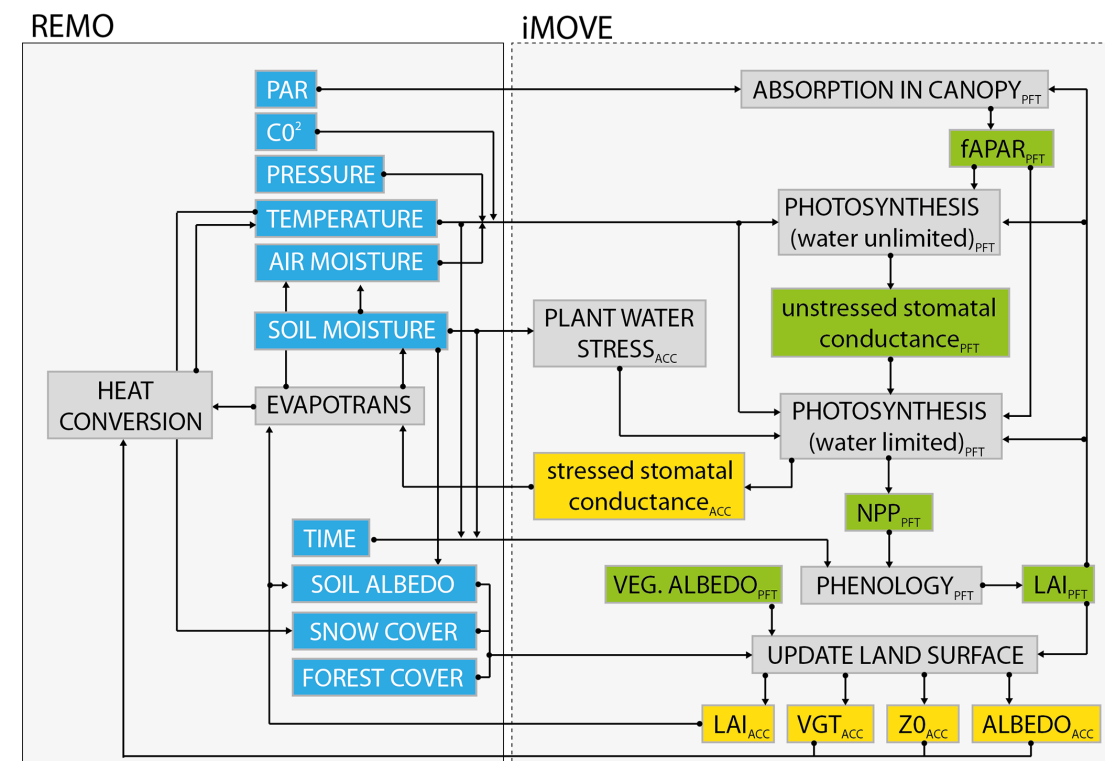

Figure 1. Coupling concept of REMO-iMOVE.

water is present ( $>90 \%$ of $\mathrm{WS}_{\max }$ ). If the water availability is limited $\left(<90 \%\right.$ of $\left.\mathrm{WS}_{\max }\right)$ the resistance against bare soil evaporation will increase $\left(\eta_{\text {bare }}=55 \%\right)$. If the soil water drops to minimum values $\left(<35 \%\right.$ of $\left.\mathrm{WS}_{\max }\right)$, the bare soil evaporation is rather inhibited ( $\eta_{\text {bare }}=90 \%$ ).

The introduced method distinctly improves the standard parameterization in REMO, even if it is far from perfect. A clear disadvantage of the scheme is that it does not capture the transition zones in bare soil evaporation regimes. This can only be overcome by a soil hydrological parameterization with a multi-layer soil model, but that was beyond the scope of this coupling study.

\subsubsection{Coupling between REMO and JSBACH}

REMO and JSBACH are technically very similar. This similarity made it possible to implement subroutines of JSBACH directly into the REMO model code. Therefore, the coupling between the two models could be realized on a model time step basis without significant loss of computational performance. This is because the model physics, which the new model constituents are based on, only take minimal computation time compared to other parts of REMO. Figure 1 shows the concept of the coupling and the computations done by the iMOVE (JSBACH) sub-model. Here we show only the most important parameters and processes. In the left box the directly concerned processes and parameters of standard REMO are shown in blue and grey. On the right-hand side the new processes and parameters are shown in green, yellow and grey. Green parameters mean that a quantity is processed for each PFT of a grid cell. Yellow parameters are accumulated as a weighted PFT average for the grid cell and reported back to REMO. Grey boxes represent processes.
The canopy absorption model of iMOVE gets the photosynthetically active radiation of REMO and together with the LAI for each PFT the fAPAR is computed (ABSORPTION IN CANOPY). fAPAR is used together with atmospheric $\mathrm{CO}_{2}$, pressure, temperature, atmospheric moisture and LAI to derive the water-unlimited photosynthesis rate and unstressed stomatal conductance (PHOTOSYNTHESIS water unlimited). The water stress factor is computed using the soil water content of REMO (the hydrological soil parameterizations in REMO and ECHAM6 are similar). The photosynthesis rate and stomatal conductance are computed using unstressed quantities combined with the computed water stress factor (PHOTOSYNTHESIS water limited). The actual photosynthesis rate is the basis for the net primary production (NPP). The actual stomatal conductance is given back to REMO to compute the surface evaporation fluxes. NPP, soil moisture, temperature and the model time step are used in the phenology model to derive the updated LAI (PHENOLOGY). The surface vegetation ratio (VGR) is derived from the LAI via Beers extinction law for each PFT. The VGR for the whole grid cell is based on weighted PFT values. The grid cell albedo is updated using soil albedo, vegetation albedo, snow cover, and the water fraction, if open water is present in the grid cell. The grid cell roughness length ( $\mathrm{Z} 0)$ is computed using vegetation and soil roughness length on weighted PFT basis (UPDATE LAND SURFACE). The updated and accumulated physical surface parameters for each grid cell VGR, LAI, albedo and Z0 are passed to the surface flux computations of REMO. The dynamic coupling of surface and vegetation processes to the atmosphere represents interactions between land and atmosphere and hence adjusts the surface parameters based on the atmospheric forcing. In turn, the surface and vegetation feed back to the atmospheric state. 
Table 3. Allocation of GLC2000 class mosaic vegetation (grassland/shrubland/forest) (50-70\%)/cropland (20-50\%) to PFTs according to the Holdridge ecosystem classes.

\begin{tabular}{|c|c|c|c|c|c|c|}
\hline \multirow[t]{2}{*}{ Biotemp $\left[{ }^{\circ} \mathrm{C}\right]$} & \multicolumn{6}{|c|}{ Precipitation [mm] } \\
\hline & $<125$ & 125 to $<250$ & 250 to $<500$ & 500 to $<1000$ & 1000 to $<2000$ & $>2000$ \\
\hline \multirow{3}{*}{$<3$} & PFT 13: $35 \%$ & PFT 13: $35 \%$ & PFT 13: $35 \%$ & PFT 13: $35 \%$ & PFT 13: $35 \%$ & PFT 13: $35 \%$ \\
\hline & PFT 12: $30 \%$ & PFT 12: $30 \%$ & PFT 12: $30 \%$ & PFT 12: $30 \%$ & PFT 12: $30 \%$ & PFT 12: $30 \%$ \\
\hline & PFT 11: $35 \%$ & PFT 11: $35 \%$ & PFT 11: $35 \%$ & PFT 11: $35 \%$ & PFT 11: $35 \%$ & PFT 11: $35 \%$ \\
\hline \multirow[t]{3}{*}{3 to $<6$} & PFT 13: $40 \%$ & PFT 13: $40 \%$ & PFT 13: $40 \%$ & PFT 13: $40 \%$ & PFT 13: $40 \%$ & PFT 13: $40 \%$ \\
\hline & PFT 9/10: $60 \%$ & PFT 9/10: $60 \%$ & PFT 9/10: $60 \%$ & PFT 9/10: $45 \%$ & PFT 9/10: $40 \%$ & PFT 9/10: $40 \%$ \\
\hline & & & & PFT 5: $15 \%$ & PFT 5: $20 \%$ & PFT 5: $20 \%$ \\
\hline \multirow[t]{5}{*}{6 to $<12$} & PFT 13: $40 \%$ & PFT 13: $40 \%$ & PFT 13: $40 \%$ & PFT 13: $40 \%$ & PFT 13: $40 \%$ & PFT 13: $40 \%$ \\
\hline & PFT 4: $10 \%$ & PFT 4: $20 \%$ & PFT 4: $20 \%$ & PFT 4: $25 \%$ & PFT 4: $25 \%$ & PFT 4: $30 \%$ \\
\hline & PFT 5: $10 \%$ & PFT 5: $20 \%$ & PFT 5: $20 \%$ & PFT 5: $20 \%$ & PFT 5: $25 \%$ & PFT 5: $30 \%$ \\
\hline & PFT 8: $10 \%$ & PFT 8: $10 \%$ & PFT 8: $10 \%$ & PFT 9/10: $15 \%$ & PFT 9/10: $10 \%$ & \\
\hline & PFT 9/10: $30 \%$ & PFT 9/10: $10 \%$ & PFT 9/10: $10 \%$ & & & \\
\hline \multirow[t]{5}{*}{12 to $<24$} & PFT 13: $40 \%$ & PFT 13: $40 \%$ & PFT 13: $40 \%$ & PFT 13: $40 \%$ & PFT 13: $40 \%$ & PFT 13: $60 \%$ \\
\hline & PFT 9/10: $60 \%$ & PFT 7: $35 \%$ & PFT 4: $20 \%$ & PFT 4: $25 \%$ & PFT 4: $20 \%$ & PFT 4: $20 \%$ \\
\hline & & PFT 9/10: $25 \%$ & PFT 5: $15 \%$ & PFT 5: $10 \%$ & PFT 5: $20 \%$ & PFT 5: $20 \%$ \\
\hline & & & PFT 7: $15 \%$ & PFT 7: $15 \%$ & PFT 7: $20 \%$ & PFT 7: $20 \%$ \\
\hline & & & PFT 9/10: $10 \%$ & PFT 9/10: $10 \%$ & & \\
\hline \multirow[t]{3}{*}{$>24$} & PFT 13: $40 \%$ & PFT 13: $40 \%$ & PFT 13: $40 \%$ & PFT 13: $40 \%$ & PFT 13: $40 \%$ & PFT 13: $40 \%$ \\
\hline & PFT 7: $30 \%$ & PFT 7: $30 \%$ & PFT 2: $10 \%$ & PFT 2: $40 \%$ & PFT 1: $40 \%$ & PFT 1: $50 \%$ \\
\hline & PFT 9/10: $30 \%$ & PFT 9/10: $30 \%$ & PFT 7: $50 \%$ & PFT 7: $20 \%$ & PFT 7: $20 \%$ & PFT 8: $10 \%$ \\
\hline
\end{tabular}

\section{Experiments}

To check the performance of REMO-iMOVE in comparison to standard REMO we conduct two 11-year simulations under past climate conditions from 1995 to 2005 for the European continent on $0.44^{\circ}$ resolution. The models are forced with so-called perfect lateral boundary conditions ECMWF ERA-Interim (Simmons et al., 2006) at $0.7^{\circ}$ resolution. To bring the soil thermal properties into equilibrium with the climate, a soil spin-up of 3 years is run beforehand. The soil hydrological conditions are not put into equilibrium to check the adjustment of vegetation cover in the first year. Figure 2 depicts the orography of the model domain projected on a globe.

\section{Reference data sets}

As reference to compare the climatic parameters of the two model runs against, various observational data sets were used. Not all data sets were available for the whole simulation period. For those, the available period was compared. For each observed parameter the monthly mean values averaged over the available time period were compared against the simulations. All observational data sets were remapped to the model grid at $0.44^{\circ}$ resolution.

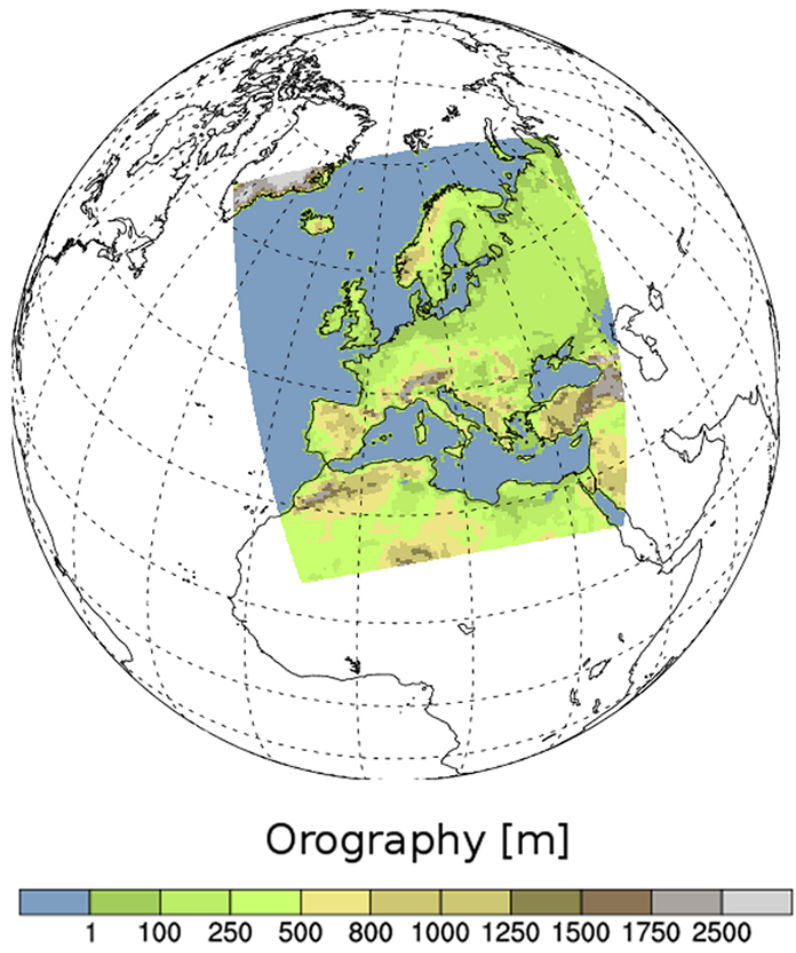

Figure 2. Domain of the reference climate model runs with REMO2009 and REMO-iMOVE. 
As reference data set for $2 \mathrm{~m}$ temperature we use the gridded data sets of the Climate Research Unit version 3.0 (CRU) at $0.5^{\circ}$ resolution (Mitchell and Jones, 2005) and the observational data set of the EU FP6 Ensembles project (E-OBS) at $0.5^{\circ}$ resolution (Haylock et al., 2008), to get an observation data spread for this parameter. As observational data set for precipitation the CRU version 3.0 product at $0.5^{\circ}$ resolution and the Global Precipitation Climatology Centre (GPCC) data at $1.0^{\circ}$ resolution (Rudolf and Schneider, 2004) are used, also to get a spread in the observations for this parameter. Surface latent heat fluxes are compared against gridded FLUXNET data at $1 \mathrm{~km}$ resolution, processed and published by Jung et al. (2011). The data set is available for the years 1996 to 2001, which is used for the comparison. The simulated annual LAI cycle is compared against the CYCLOPES LAI product at $1 \mathrm{~km}$ resolution (Baret et al., 2007). Uncertainties in satellite LAI estimations are known and result mainly from unstable retrieval of LAI from surface reflectances. These can bias satellite-derived LAI magnitudes under some circumstances by $50 \%$ (Garrigues et al., 2008). Despite those uncertainties, CYCLOPES data are evaluated against in situ data and show good agreement for all land cover types, except for dense vegetation where LAI is underestimated (Weiss et al., 2007; Garrigues et al., 2008). To evaluate the LAI we employed the described CYCLOPES data for the years 2002 and 2003.

\section{Results}

\subsection{Comparison between REMO2009 and REMO-iMOVE}

The modifications in the model REMO-iMOVE result mainly in changes of surface characteristics like albedo, LAI, vegetated part of the grid cell, roughness length, stomatal conductance or plant-available soil water. These variables play an important role in modelling the near-surface climate as mentioned above. In this section, we compare simulation results of the two model versions REMO2009 and REMOiMOVE for the 10-year time period 1996 to 2005. We will also introduce the new model features of REMO-iMOVE and their importance for climate simulations. We evaluate the model versions on a monthly basis, to be able to describe differences in sub-seasonal processes like snow melting or crop harvesting, which could not be seen in seasonal plots.

First, an overview of changes in the near-surface temperature, precipitation and latent heat flux characteristics is given. In this more general insight, we identify areas where the model versions differ to a large degree. In a second step, we evaluate regions where most distinct modifications occur, in order to understand associated processes. Then, we apply the climate classification of Köppen-Geiger (Koeppen, 1900) to distinguish between different climatic regimes subdivided by regional characteristic units of European landscapes.

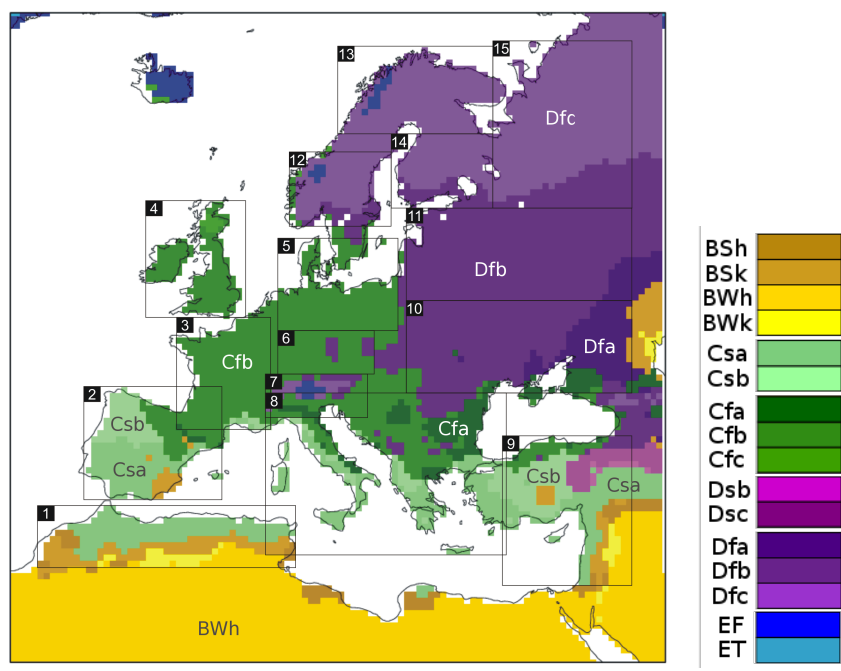

Figure 3. Climate types based on the Köppen-Geiger climate classification and evaluation regions for the model domain.

Figure 3 shows the distribution of climate types and the landscape units. The climate types are briefly explained in Table 4 .

\subsubsection{Overview: $2 \mathrm{~m}$ temperature}

In Fig. $4 a$ and $b$ the deviation of the near-surface temperature (at $2 \mathrm{~m}$ height) compared to CRU is shown in Kelvin. In the winter months a pronounced large-scale warm bias reaching up to $3 \mathrm{~K}$ over Scandinavia is visible. This bias is reduced in spatial extent in January, but still high in magnitude. It declines until April and reappears again in November. Contrasting to the warm bias, a large-scale cold deviation is evident in most parts of the northeastern domain. The cold deviation with magnitudes of more than $-3 \mathrm{~K}$ begins to appear in December and strengthens in magnitude and spatial extent until April. It is more pronounced in REMO2009 than in REMOiMOVE, where especially in March and April the magnitude and extent is significantly reduced. A large-scale cold bias in May in REMO2009, also in the northeastern part of the domain, reaches values up to $-2 \mathrm{~K}$. This deviation is largely reduced in REMO-iMOVE.

The Balkans and the northeastern shore of the Black Sea show a warm deviation with magnitudes up to $2.5 \mathrm{~K}$ from December to March in REMO2009 (see evaluation regions 8 - Cfb climate and evaluation region 10). This deviation is reduced in REMO-iMOVE, where it totally disappears in March in that region. The months April, May and June are simulated well in both versions. Nevertheless, REMOiMOVE shows a slightly stronger overestimation of up to $1 \mathrm{~K}$ in western and central Europe (evaluation regions 3, 5 and 6) compared to REMO2009. 
Table 4. Köppen-Geiger climate types used for model evaluation.

\begin{tabular}{ll}
\hline B & Arid climates \\
\hline BSh & Hot steppe climate \\
BSk & Cold steppe climate \\
BWh & Hot desert climate \\
BWk & Cold desert climate \\
\hline C & Warm temperate climates \\
\hline Csa & Warm temperate climate with dry hot summer \\
Csb & Warm temperate climate with dry warm summer \\
Cfa & Warm temperate climate fully humid with hot summer \\
Cfb & Warm temperate climate fully humid with warm summer \\
Cfc & Warm temperate climate fully humid with cold summer \\
\hline D & Snow climates \\
\hline Dsb & Snow climate summer dry, warm summer \\
Dsc & Snow climate summer dry, cold summer \\
Dfa & Snow climate fully humid, hot summer \\
Dfb & Snow climate fully humid, warm summer \\
Dfc & Snow climate fully humid, cold summer \\
\hline E & Polar climates \\
\hline ET & Tundra climate \\
EF & Frost climate \\
\hline
\end{tabular}

From July on, REMO-iMOVE shows a significant warm feature in magnitude of up to $2.5 \mathrm{~K}$ over southwestern Spain, Italy, the Balkans and the North African shoreline (evaluation regions 1 - Csa climate, 2 - Csa climate, 8, partly 10). REMO2009 also simulates the warm feature in southern Spain, Italy and North Africa. In August the warm biases in both model versions still persist, with a significant warm bias over the Balkans unique for REMO-iMOVE (evaluation region 8 - Cfa and $\mathrm{Cfb}$ climates). The bias in southwestern Spain in contrast is relieved in REMO-iMOVE compared to REMO2009. September and October show a large-scale warm bias in REMO-iMOVE over central Europe (evaluation regions 5, 6, 7, 8 - Cfa and Cfb climates, western part of region 10) reaching magnitudes up to $1.5 \mathrm{~K}$. These features are less pronounced, but also present in REMO2009. In the summer months of June, July and August a cold deviation is visible in REMO2009 over the whole of eastern Europe (Dfb climate of evaluation region 10 and 11) with magnitudes up to $-1.5 \mathrm{~K}$. This cold bias is no longer evident in REMO-iMOVE. A large-scale cold feature over the Saharan belt is visible in both model versions all over the year with deviations reaching more than $-3 \mathrm{~K}$. When comparing to the E-OBS data set (not shown) the main deviations described here show the same patterns, even if the magnitudes differ slightly.

\subsubsection{Overview: precipitation}

In Fig. 5a and $\mathrm{b}$ the relative difference of precipitation compared to CRU observational data is shown in percent. The first feature visible is the strong deviation in the Saharan belt, which is produced when looking at relative differences of very small numbers in percent. A quantitative comparison is usually not done for such regions and will also not be done here.

In winter and early spring until April, both models show similar deviation patterns with a large-scale overestimation of precipitation by 40 to $60 \%$ for the whole of central and northern Europe. An exception from this general overestimation in winter are the British Isles, which show an underestimation with magnitudes up to 40 to $60 \%$ over the whole year. Also in mountainous terrain (Alps, Balkans, Caucasus) and partly in Spain and Italy an underestimation of precipitation is depicted with magnitudes ranging up to $80 \%$. In May, we see distinct differences between the model versions. While REMO2009 still shows an overestimation in the whole of central and northern Europe, REMO-iMOVE simulates an underestimation of precipitation over the northern Balkans (evaluation region $8-\mathrm{Cfb}$ climate). This feature persists and grows in magnitude and extent until September and October (evaluation regions 8, 6, partly 5 and 3). REMO2009 simulates an equally large dry bias in extent and magnitude in August, September and October also for the Balkans region. In September REMO2009 shows an intensive dry bias located over the Balkans, with large-scale magnitudes of up to $100 \%$ less precipitation. This bias is apparent in REMOiMOVE also, but its magnitude is reduced in most parts. Italy and Greece show a distinct dry bias in both model versions in autumn, with deviations of up to $80 \%$ less precipitation amount.

The simulated precipitation was also compared to GPCC observational data. The panels are not shown here, but as a general noticeable feature, the overestimation of precipitation over central and northern Europe remains, equal to the picture shown when compared to CRU, although the deviation magnitude is smaller and regional differences occur.

The period December to March in contrast, shows an underestimation in parts of western and central Europe in both models.

An important point is the reduction of the dry bias over mountainous areas, especially the Alps and the Caucasus. These areas, in contrast to their comparison to CRU, show an overestimation when compared to GPCC. The summer and autumn dry bias over the Balkans and central Europe in REMO-iMOVE persists in this comparison. A remarkable feature is the intensive dry bias in REMO2009 over the Balkans with magnitudes of up to $100 \%$ less precipitation. Although the bias is evident in REMO-iMOVE also, its magnitude is strongly reduced. The autumn dry bias in Italy and Greece is also a common feature for both models, when compared to GPCC. 


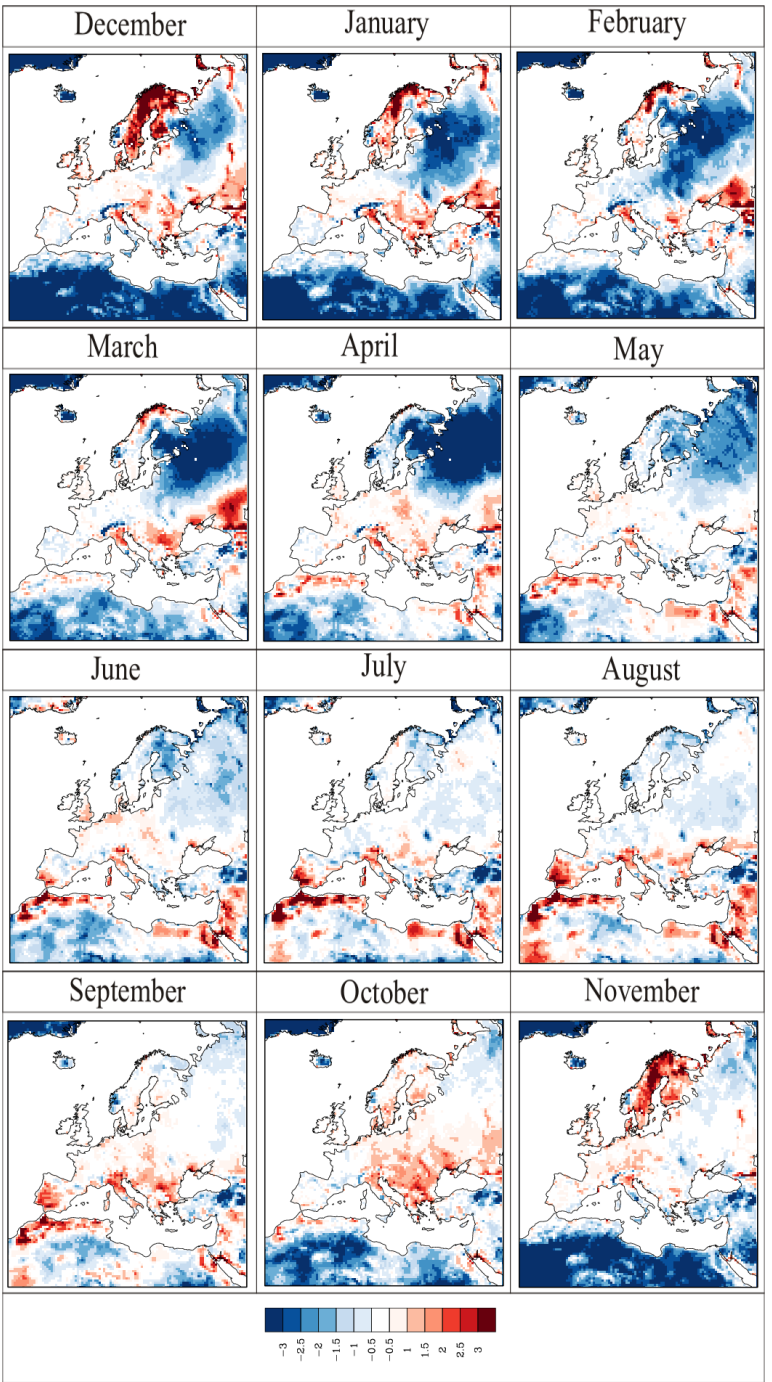

4 a) REMO2009 - CRU

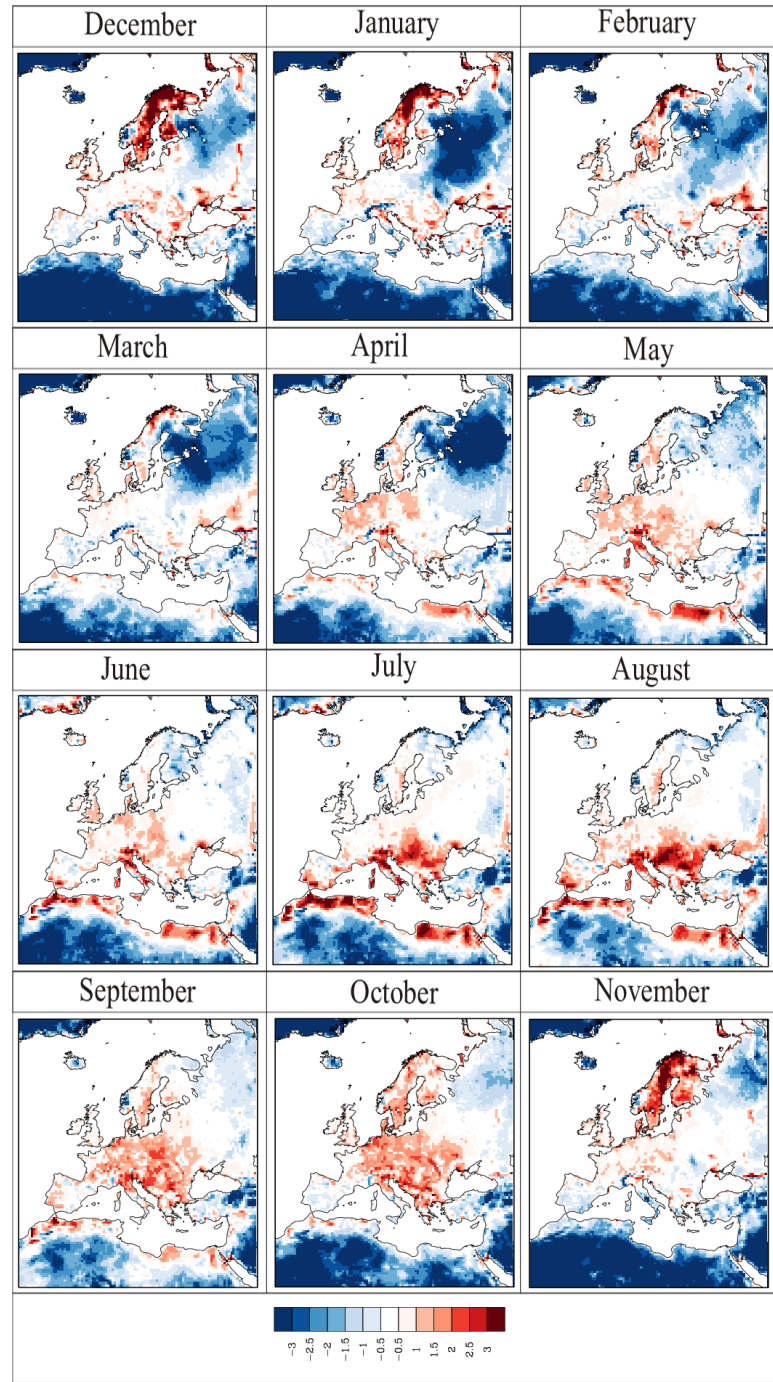

4 b) REMO-iMOVE - CRU

Figure 4. Differences of $2 \mathrm{~m} T$ of REMO2009 vs. CRU and REMO-iMOVE vs. CRU in the period 19962005.

\subsubsection{Overview: latent heat flux}

Figure $6 \mathrm{a}$ and $\mathrm{b}$ show the deviation of the simulated latent heat flux against gridded FLUXNET data. Please note, that fluxes are defined negative when the flux is directed from the surface to the atmosphere. From November to March, deviations are small due to the energy limitation for evaporation by incoming solar radiation. From May to August, REMO2009 severely overestimates the latent heat flux over the whole European continent by up to $50 \mathrm{~W} \mathrm{~m}^{-2}$. The extreme cases can be seen in the Mediterranean region and Kazakh Steppe regions (evaluation region 10 - Dfa and BWh climates). In REMO2009 an underestimation takes place in late summer and autumn in the Mediterranean and North African regions. REMO-iMOVE shows similar overestimations like REMO2009, but with lower magnitudes simulated by REMO2009, except for Turkey and northern Spain. In July and August, both model versions show an underestimation in the Hungarian Basin and the Danube delta area. This feature is more pronounced in REMO-iMOVE than it is in REMO2009. In September and October, results of REMOiMOVE show a slight underestimation of latent heat flux over western and central Europe and the Balkans. REMO2009 shows such a behaviour over Spain. A distinct difference between the model versions is the simulated result in May over northern Scandinavia. Here, REMO2009 shows an overestimation of up to $+20 \mathrm{~W} \mathrm{~m}^{-2}$, whereas REMO-iMOVE shows the opposite.

In Sects. 5.1.1, 5.1.2 and 5.1.3 two main regions can be identified where differences in the model versions REMO2009 and REMO-iMOVE are most pronounced: 


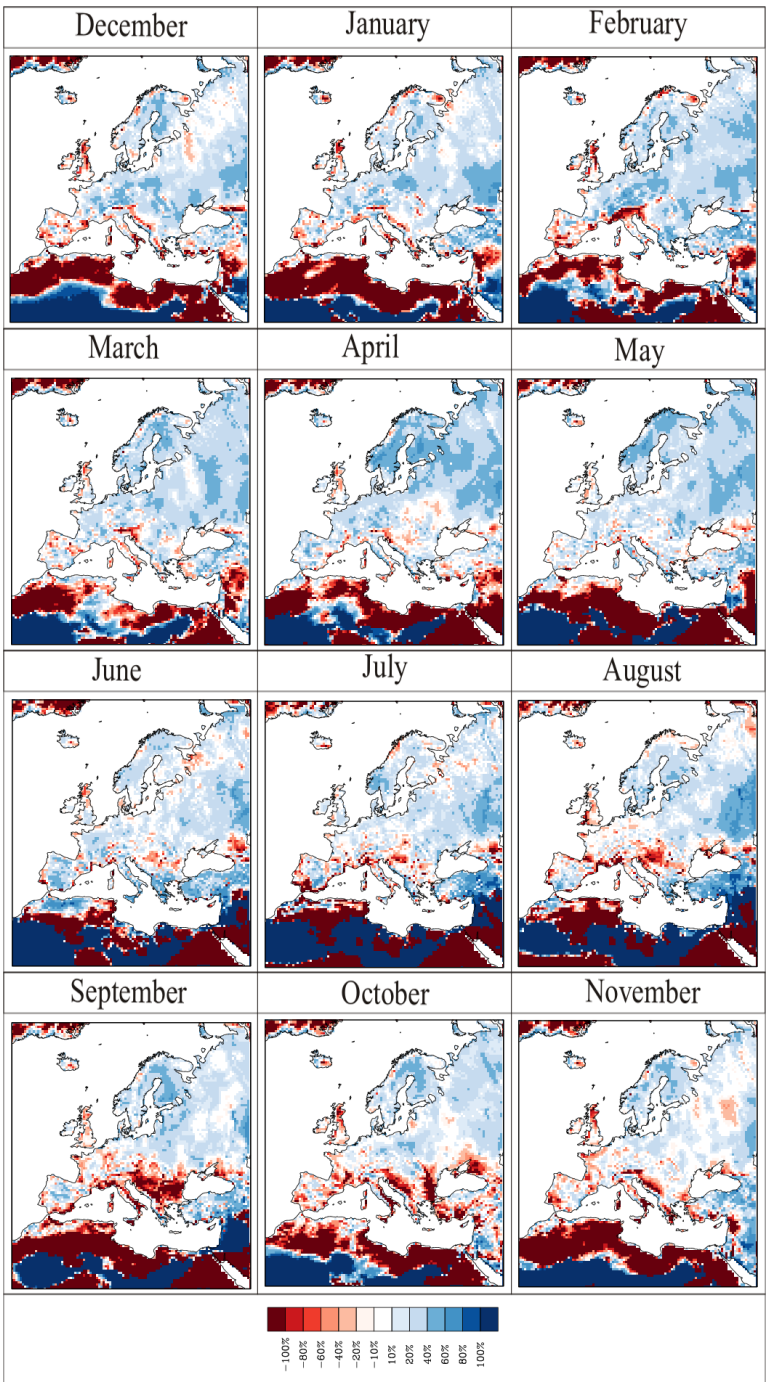

5 a) REMO2009 - CRU

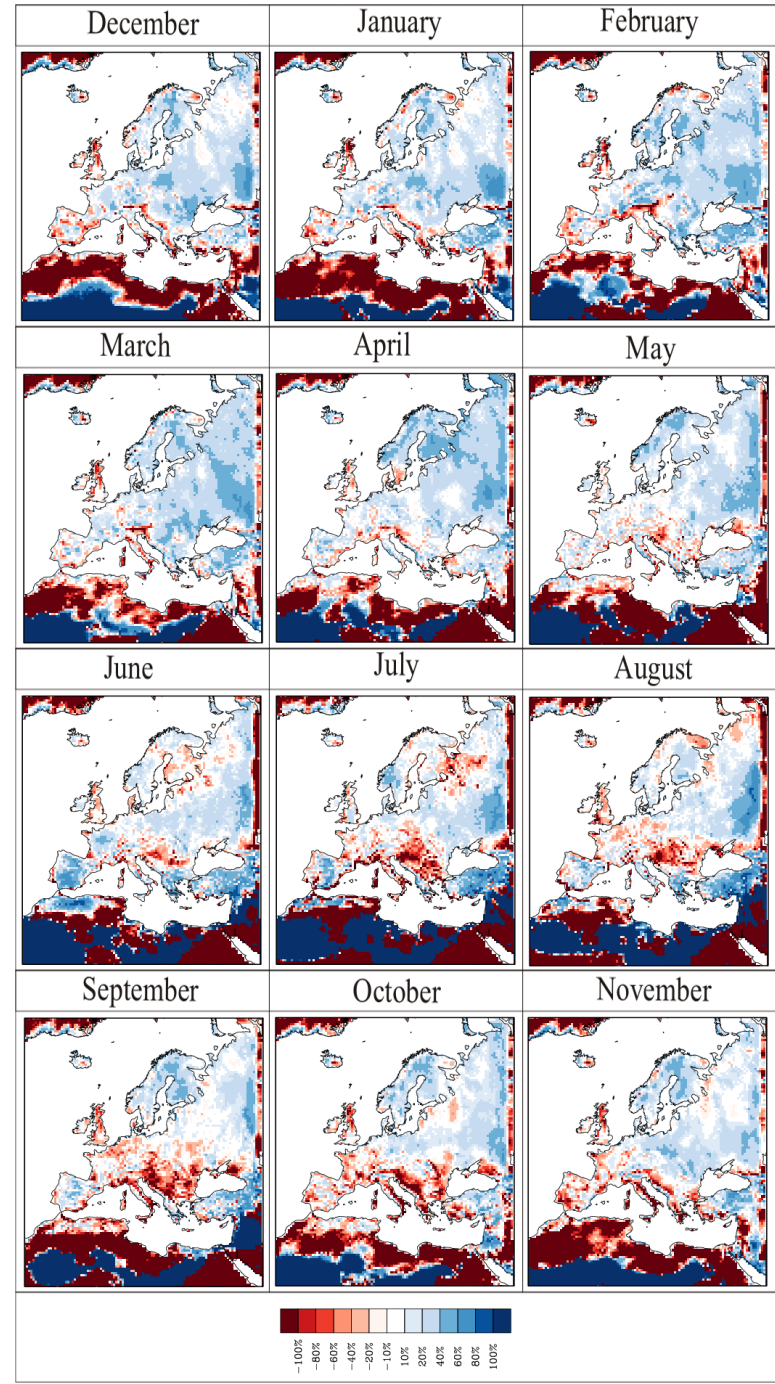

5 b) REMO-iMOVE - CRU

Figure 5. Differences of total precipitation of REMO2009 vs. CRU and REMO-iMOVE vs. CRU in the period 1996 to 2005.

- The northeastern parts of the domain, where the cold bias in REMO2009 from February to May is reduced in magnitude and spatial extent in REMO-iMOVE (mainly evaluation regions 11 and 15).

- The Balkans, Hungarian Lowlands and the west coast of the Black Sea, where the warm bias of REMO2009 from July until October - also called summer drying phenomenon - is increased in extent and strength in REMO-iMOVE. This feature can be entangled with a distinct precipitation and latent heat flux reduction in REMO-iMOVE (mainly evaluation regions 8 and 10).

In Sects. 5.1.4 and 5.1.5, we discuss the major differences between the simulation results and how they are related to physical processes represented in the two model versions.

\subsubsection{Reduction of the cold bias in the northeastern part of the domain in winter}

The reduction of the cold bias in the northeast of the domain in REMO-iMOVE is related to the fact that the forest cover in that part is increased by 30 to $40 \%$ in a large areal extent (Fig. 7). If forest is present in snow-covered landscapes, the albedo of snow which normally uniformly covers the surface is reduced, resulting in less effective radiation reflection. If forest is present the snow albedo in the model $\alpha_{\text {snow }_{\text {forest }}}$ is a function of the surface temperature and the forest fraction $f_{\text {forest }}$ of the grid cell. For $T_{\mathrm{s}} \leq-10^{\circ} \mathrm{C}$ the albedo is fixed to a maximum value for $\alpha_{\text {snow forest }}$. For $-10^{\circ} \mathrm{C}<T_{\mathrm{s}}<0{ }^{\circ} \mathrm{C}$ the snow albedo decreases linearly until the minimum value of $\alpha_{\text {snow forest }}$ is reached at $T_{\mathrm{s}}=0^{\circ} \mathrm{C}$. The maximum and minimum values of $\alpha_{\text {snow }_{\text {forest }}}$ depend further on the forest fraction 


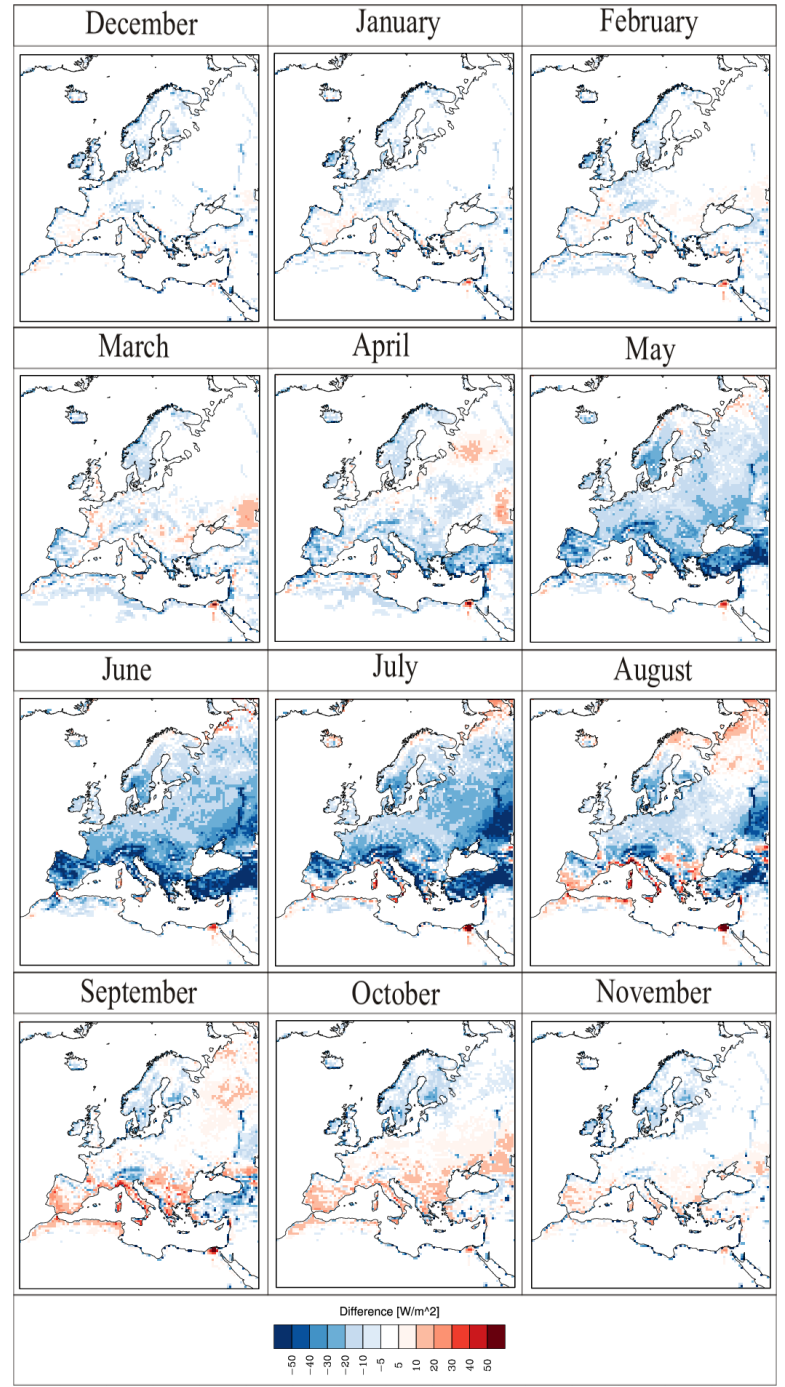

6 a) REMO2009 - FLUXNET

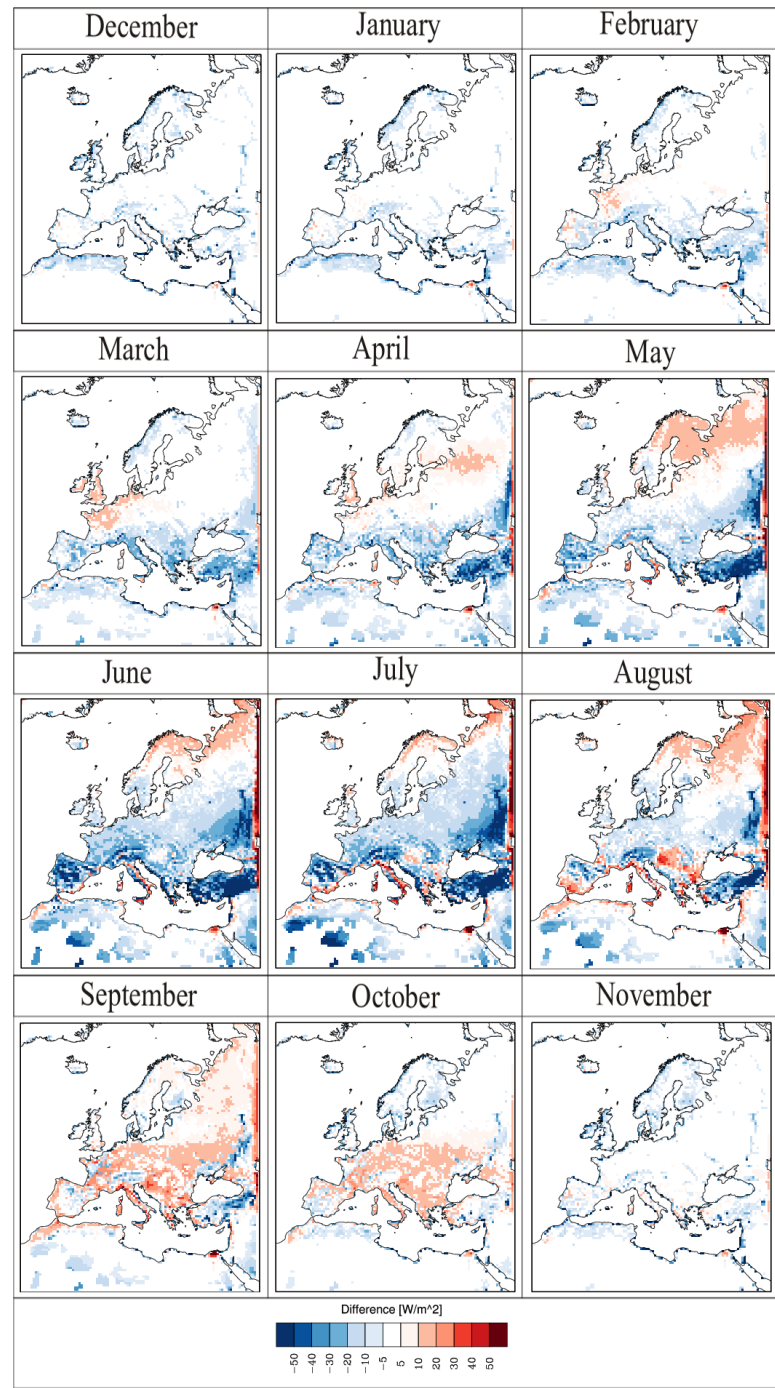

6 b) REMO-iMOVE - FLUXNET

Figure 6. Differences of surface latent heat flux of REMO2009 vs. FLUXNET and REMO-iMOVE vs. FLUXNET in the period 1995 to 2001.

$f_{\text {forest }}$ and vary from 0.4 to 0.8 and from 0.3 to 0.4 , respectively. The lower value is valid for maximum forest fraction $f_{\text {forest }}=1$, the higher value for minimum forest cover $f_{\text {forest }}=0$ (Kotlarski, 2007).

Figure 8 shows the differences in surface albedo between the model versions and the snow depth in REMO-iMOVE (REMO2009 is not shown but is almost equal). The distinct decrease in reflectance is correlated to the presence of snow and the increase in forest fraction.

The reduction of the snow-masking effect and the decrease of soil albedo cannot be the reason for the reduction of the cold bias in May, since no snow is present and the albedo is increased in REMO-iMOVE. The $2 \mathrm{~m}$ temperature increase in REMO-iMOVE is correlated with a decrease in LAI (not shown). This results in a change of the Bowen ratio towards the sensible heat flux and less evaporative cooling of surface temperatures.

\subsubsection{Increase of the warm bias in central eastern Europe from July to October}

Mainly the areas of the Balkans, the Hungarian Lowlands and the west coast of the Black Sea are under the influence of a distinct increase in $2 \mathrm{~m}$ temperatures in REMO-iMOVE from July until October (evaluation region $8-\mathrm{Cfa}$ and $\mathrm{Cfb}$ climate). The areas showing the warm deviation correlate with a drop in LAI and vegetation ratio (vegetation-covered part of the grid cell - VGR) in REMO-iMOVE (Fig. 9). This decrease in vegetated area decreases the effective amount of transpiration and thus evaporative cooling. This causes an 


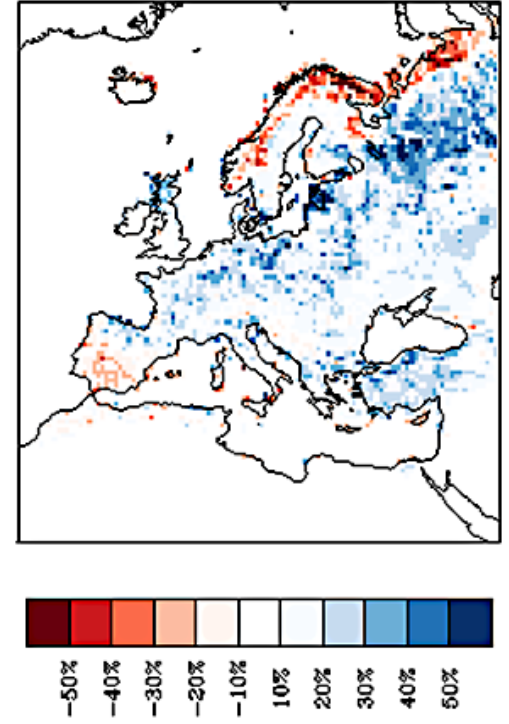

Figure 7. Differences in forest cover between REMO-iMOVE and REMO2009.

increase in temperature and sensible heat flux (please note: fluxes are defined negative when directed away from the surface). The increased Bowen ratio causes a drying of the lower atmosphere. The lower atmospheric moisture provides an important part to the whole atmospheric moisture content. Especially in summer, when the local moisture recycling is the main source for precipitation, the decrease in atmospheric moisture is the reason for a reduction in precipitation. The reason for the changes in the vegetation surface parameters LAI and VGR is the improved phenology scheme for crops. In REMO2009, the crops are harvested at a fixed date every year, which is decoupled from the climatic drivers and occurs in late September. The crop phenology in REMO-iMOVE is closely coupled to the atmospheric forcing and thus is able to model the harvest date dynamically - in this case the end of August, beginning of September. Figure 10 shows the LAI annual cycles of both model versions and the CYCLOPES observation data in 2002 and 2003 for the Cfa climate in evaluation region 8 (compare Fig. 3). The simulated LAI in REMO-iMOVE closely matches the characteristics of the observational data, not only in magnitude but also in the timing of maximum and minimum values, which is not the case in REMO2009.

\subsection{New model features in REMO-iMOVE}

In this section, we introduce new parameters and processes which are now represented in REMO-iMOVE.

The introduction of PFTs enables the model to simulate plant physiological behaviour and its direct feedback to the atmosphere. Modelling plant physiological behaviour using the described approach in a regional climate model sets up the basics for climate-ecological experiments on detailed resolution.
The model now takes into account the influence of atmospheric $\mathrm{CO}_{2}$ concentration to plant stomatal conductance and therefore to surface evaporation. This effect is long known (Betts et al., 1997; Avissar and Pielke, 1991) and some studies show the effects for historical climate simulations (Jeong et al., 2010; Cao et al., 2010). An important point in this respect is the ability of the new model system REMO-iMOVE to connect atmospheric forcing and vegetation response on a model time step basis.

An advantage in terms of climate variability is the interactive coupling of phenology to climatic drivers. Figure 10 clearly shows this advantage. REMO2009 applies a fixed annual LAI and VGR cycle, whereas REMO-iMOVE introduces a further source of inter-annual climate variability, by coupling the LAI and VGR cycle interactively to its direct atmospherical and soil hydrological drivers.

We consider the net primary productivity (NPP), which is modelled for every plant function type in the grid cell, the most important new model output. Modelling NPP directly in a regional climate model, driven by all important forcing variables, enables the modellers to conduct carbon cycle experiments at high resolution. This enhancement in resolution brings opportunities in regions of highly structured or heterogeneous terrain. In the next section we will evaluate this parameter in detail.

\subsubsection{Evaluation of the interactive phenological scheme}

The vegetation and therefore the phenological scheme of REMO-iMOVE is driven by the atmospheric forcing and soil moisture characteristics. In REMO2009 the phenology was prescribed and could not represent inter-annual variations. Figure 10 shows the LAI courses of REMO-iMOVE and REMO2009 in comparison to CYCLOPES observation data for the years 2002 and 2003. With the collection of evaluation regions shown, we give an overview for regions with high LAI dynamics. Despite some inaccuracies in the length of the vegetative period, the LAI courses of REMO-iMOVE match well with the observation data for the evaluation regions 2, 3, 5 and 8 . The LAI maximum is one month late in region 2 . The length of the vegetation period is overestimated by one month in region 5 . The vegetation period is shifted by a month in region 3, but the magnitudes of LAI match well the observations. The LAI magnitude of evaluation region 9 and 10 is highly overestimated by both models, however the timing of the onset of vegetation is captured well in REMOiMOVE. Since the phenology is now driven by atmospheric forcing, soil moisture dynamics, vegetation distribution and the phenology model logic, many factors interact to model the LAI course. The onset of vegetation greening of summergreen PFTs is mainly driven by the daily mean temperature. Thus, these PFTs are dependent on the atmospheric forcing. Grass PFTs always grow if sufficient moisture is available and the temperature is high enough. Thus, shortcomings will surely be dependent on the bucket soil scheme 


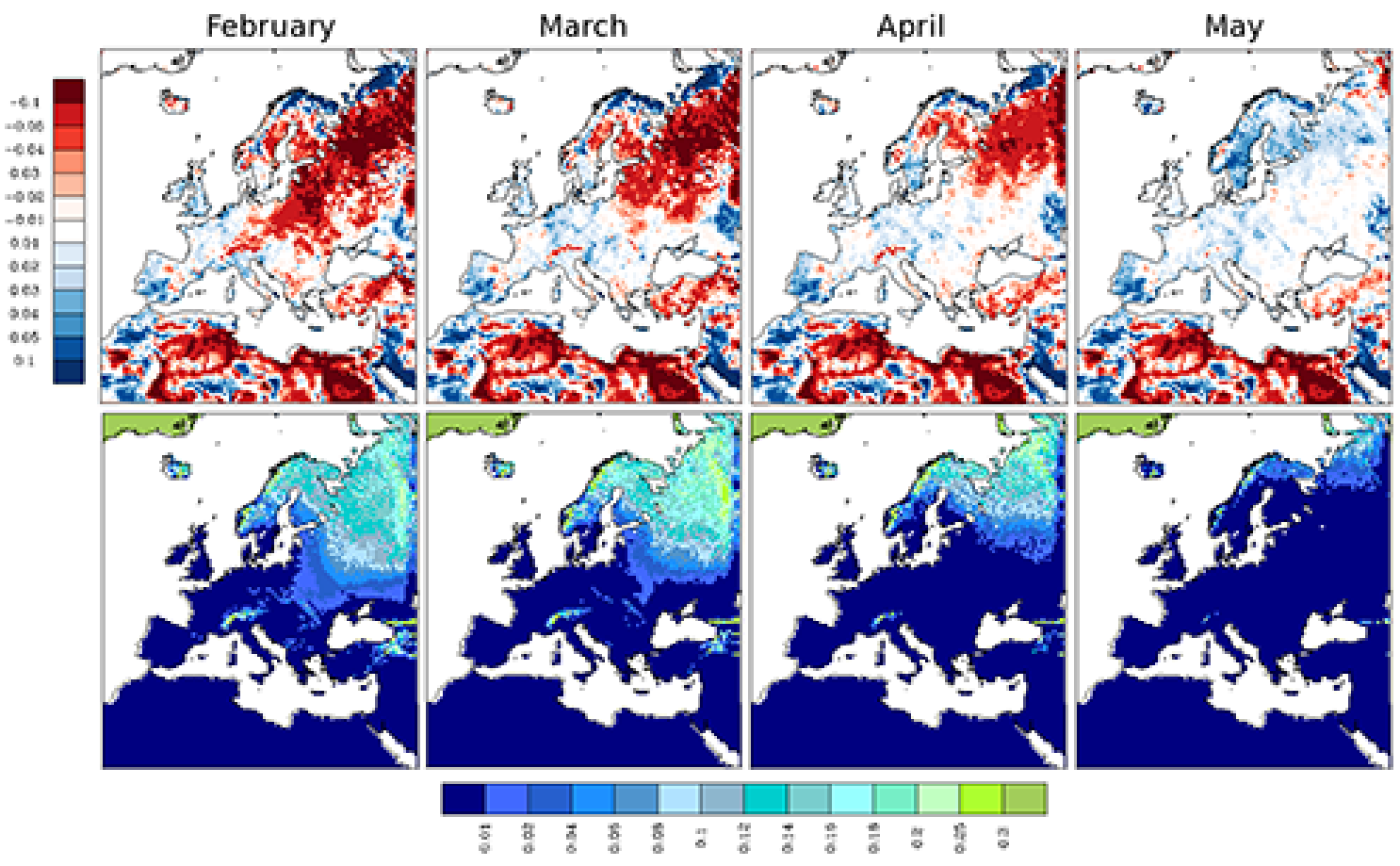

Figure 8. Differences in albedo between REMO-iMOVE and REMO2009 in reflectance percent (upper row), snow depth in REMO-iMOVE in metres (lower row).

and the atmospheric forcing. The findings also clearly show that, in comparison to REMO2009, the new model is not only able to react to inter-annual changes in vegetation cover, but also emends some shortcomings in the LAI courses of REMO2009.

\subsubsection{Evaluation of simulated net primary productivity}

To evaluate simulated NPP values by a climate model is not a straightforward task because of the following reasons. First, the simulated values are representative for a large spatial unit, in our model experiment for grid cells of $50 \times 50 \mathrm{~km}^{2}$. But productivity of plants is very dependent on local soil characteristics, plant composition and local scale weather conditions. This cannot be directly reproduced in a regional climate model at this scale. Second, plant productivity is further dependent on stand age (Roy et al., 2001), which is a parameter not modelled in REMO-iMOVE. The third point is that observed plant productivity is related to observed local weather conditions of the specific years. A regional climate model which is driven by re-analysed data still can produce somewhat different local weather conditions compared to observations in a specific grid cell at a certain time, since it simulates its "own" regional atmospheric processes inside the regional model domain.

Because of these framework conditions it is clear from the beginning that the climate model can only provide a rough estimate of plant productivity. The aim of this comparison is to show whether the simulated values can be used in transient climate projections, to be able to show how plant productivity behaves under changing climate conditions and to be able to simulate the feedback of temporal NPP variability on climate.

To get to a comparable measure for NPP, we took the areal NPP mean for each PFT in the evaluation regions (climatic regions), since these represent the climate and thus the mean growth conditions for the model years 1996 to 2005. These numbers are compared to single-point measurements taken from several free available measurement campaigns (Esser, 1998), literature values (Roy et al., 2001) and the measurements for the matching class A and class B stands taken from Olson et al. (2001) for mostly single years and single stands from 1950 to 2005 . With the given method we are able to show the natural spread of growth conditions in the evaluation region, so we can rate the modelled values on that.

In this study we use the unit gram carbon fresh matter per square metre per year $\left(\mathrm{gC} \mathrm{m}^{-2} \mathrm{a}^{-1} \mathrm{FM}\right)$. All cited values are converted from dry matter unit measurements into fresh matter values, with the use of minimum and maximum values resulting from a carbon content factor of 40 to $60 \%$ (Roy et al., 2001), and dry matter content of 10 to $30 \%$ for grassand shrubland (Roy et al., 2001) and dry matter content for trees of 16 to $42 \%$ (Shipley and Vu, 2002). Due to the use of these numbers we cover the spread in the given measurements. 


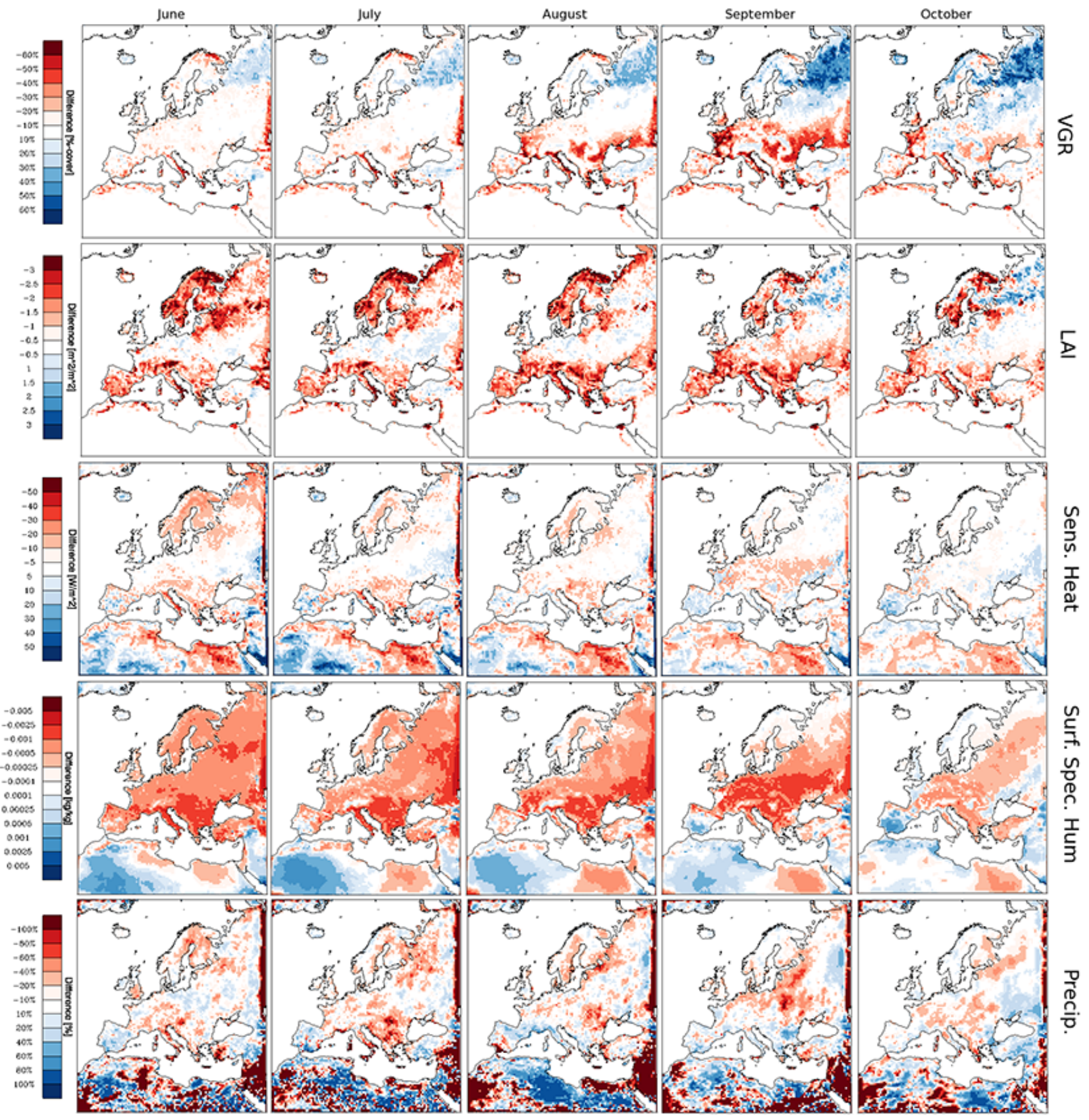

Figure 9. Differences in model parameters (LAI, vegetation ratio (VGR), sensible heat flux, surface specific humidity, precipitation) from June to October.

In the following paragraphs we will rate the plant productivity beginning with hot semi-arid environments in the south of the model domain and end with boreal woodlands and tundra in the north.
Semi-arid environments:

Since the growth of some PFTs in REMO-iMOVE is strongly influenced by the water availability, it is useful to compare the arid and semi-arid NPP values in connection to the amount of soil water. This connection is evident in nearly all these NPP courses located 

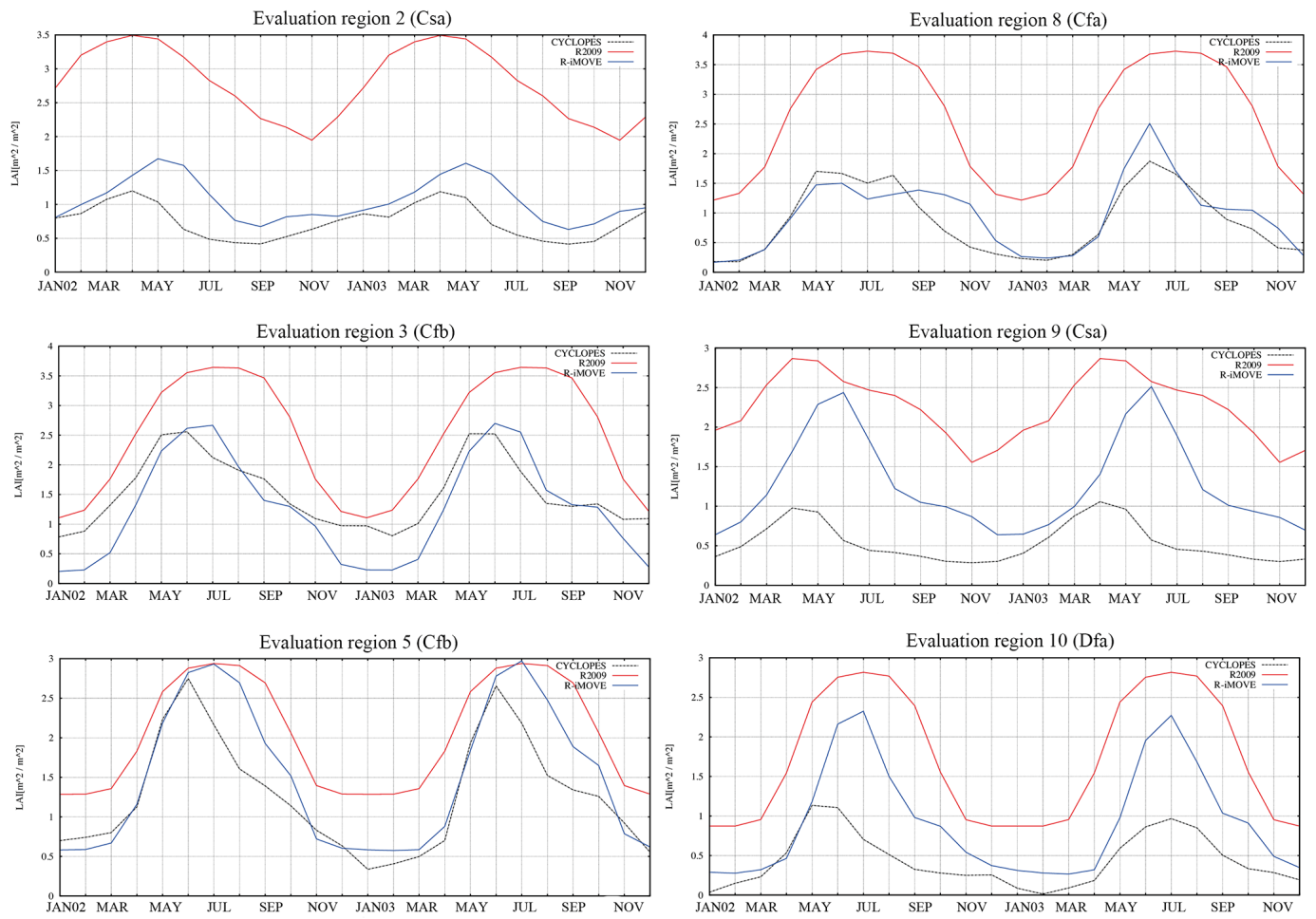

Figure 10. Annual courses of LAI in 2002 and 2003 of REMO-iMOVE, REMO2009 and CYCLOPES (compare Fig. 3).

in a semi-arid or arid environment. In the first model year, where the soil hydrology is not in equilibrium with the climate condition, the surplus water evaporates and drains out of the soil water bucket. At this time, all water-sensitive PFTs grow at maximum rates, because the photosynthesis is not limited, either by water or by radiation. After this first year spin-up, the soil water amounts for all regions is at the same level as in REMO2009 and NPP rates have been adopted to the climate type characteristics.

For these environments Olson et al. (2001) report values of 120 to $152 \mathrm{gC} \mathrm{m}^{-2} \mathrm{a}^{-1} \mathrm{FM}$ for site ID 562 from the class B measurement. Esser (1998) reports 126 to $169 \mathrm{gC} \mathrm{m}^{-2} \mathrm{a}^{-1} \mathrm{FM}$ for a stand in Algeria. The simulated values for coniferous shrubland in evaluation region 1 show values between 20 to $250 \mathrm{gC} \mathrm{m}^{-2} \mathrm{a}^{-1} \mathrm{FM}$ (see Fig. 11).

Mediterranean grassland environments:

The growth of grassland is strongly limited by the amount of water available for the plant (Roy et al., 2001). Roy et al. (2001) related NPP values of tropical grassland to days without water stress per year and found a mostly linear dependence. The NPP rates range between $500-1000 \mathrm{gC} \mathrm{m}^{-2} \mathrm{a}^{-1} \mathrm{FM}$ for about 100 days without water stress, $1000-2000 \mathrm{gC} \mathrm{m}^{-2} \mathrm{a}^{-1}$ FM for about 200 days without water stress and above $3000 \mathrm{gC} \mathrm{m}^{-2} \mathrm{a}^{-1} \mathrm{FM}$ for up to 300 days without water stress. Olson et al. (2001) report 1320 to $1672 \mathrm{gC} \mathrm{m}^{-2} \mathrm{a}^{-1} \mathrm{FM}$ for a pasture stand in Israel and 165 to $209 \mathrm{gC} \mathrm{m}^{-2} \mathrm{a}^{-1} \mathrm{FM}$ for a grassland site in Syria. Simulated values for the $\mathrm{C} 3$ and $\mathrm{C} 4$ grass PFTs show values between 0 to $3800 \mathrm{gC} \mathrm{m}^{-2} \mathrm{a}^{-1} \mathrm{FM}$ subtropical climate types (evaluation regions 1, 2, 9 see Figs. 11 and 12).

Mediterranean shrubland environments:

For Mediterranean shrubland associations we found a Mediterranean site in the class B measurement values of Olson et al. (2001), which show a spread between 525 to $665 \mathrm{gC} \mathrm{m}^{-2} \mathrm{a}^{-1} \mathrm{FM}$ in Greek Mediterranean shrubland. Roy et al. (2001) report values from 366 to $3771 \mathrm{gC} \mathrm{m}^{-2} \mathrm{a}^{-1} \mathrm{FM}$ for Mediterranean shrubland associations. The model shows values of 1600 to $2500 \mathrm{gC} \mathrm{m}^{-2} \mathrm{a}^{-1} \mathrm{FM}$ for coniferous shrubland and 600 to $2300 \mathrm{gC} \mathrm{m}^{-2} \mathrm{a}^{-1} \mathrm{FM}$ for deciduous shrubland in the Csa climate of evaluation region 8. The Csb climate of the same evaluation region shows 1800 to $3500 \mathrm{gC} \mathrm{m}^{-2} \mathrm{a}^{-1} \mathrm{FM}$ for coniferous shrubland and 700 to $2200 \mathrm{gC} \mathrm{m}^{-2} \mathrm{a}^{-1} \mathrm{FM}$ for deciduous shrubland (Fig. 13).

Mediterranean woodland environments:

For Mediterranean woodland environments we found sites of the class B measurement values of Olson 


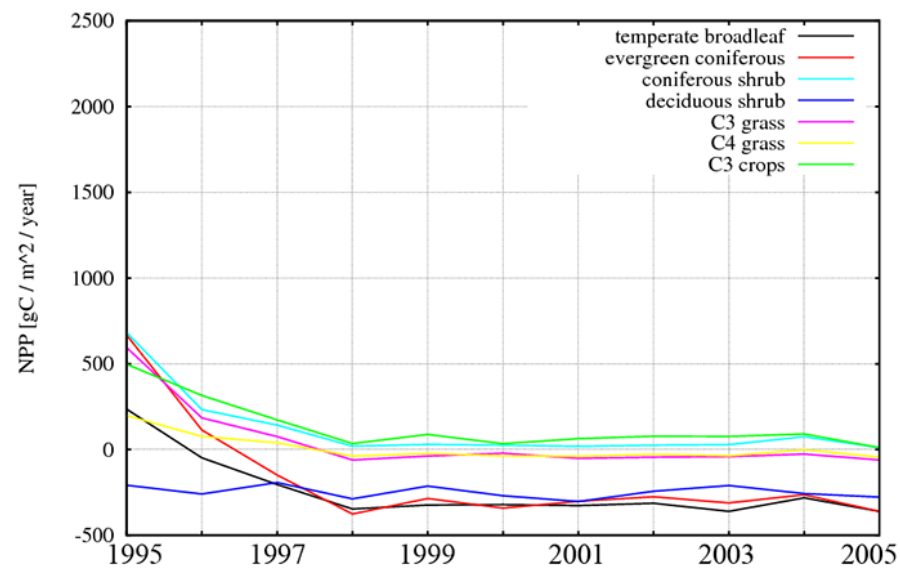

Figure 11. Net primary productivity $\left[\mathrm{gC} \mathrm{m}^{-2} \mathrm{a}^{-1} \mathrm{FM}\right]$ variations in evaluation region 1 (BW/BS climate) in the period 1995 to 2005 .

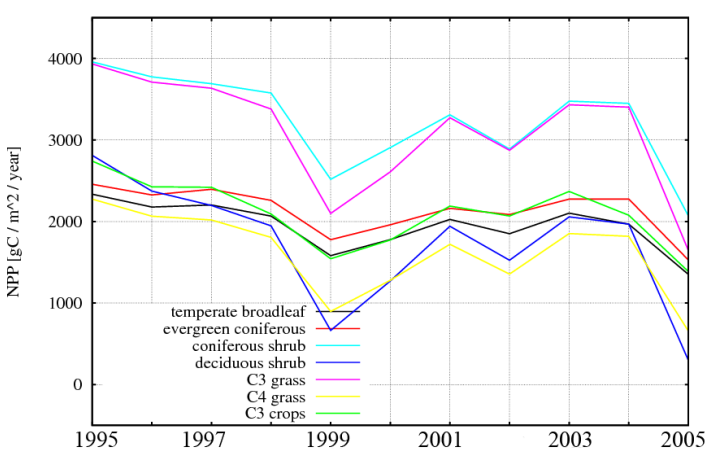

(a) Region 2 (Csb climate)

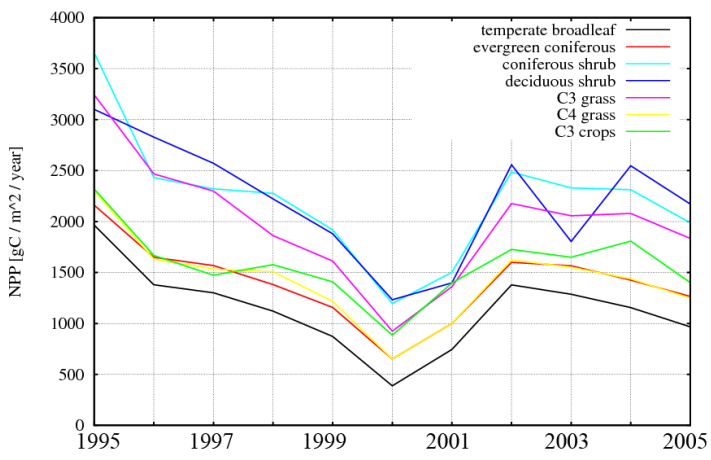

(b) Region 9 (Csa climate)

Figure 12. Net primary productivity $\left[\mathrm{gC} \mathrm{m}^{-2} \mathrm{a}^{-1} \mathrm{FM}\right]$ variations in evaluation region 2 and 9 in the period 1995 to 2005 .

et al. (2001), which show a spread between 292 to $1311 \mathrm{gC} \mathrm{m}^{-2} \mathrm{a}^{-1} \mathrm{FM}$ in French Mediterranean woodland sites. The simulated productivity of woodlands for evaluation region 3 and the $\mathrm{Csa}$ and $\mathrm{Csb}$ climate type lies between 1750 to $2100 \mathrm{gC} \mathrm{m}^{-2} \mathrm{a}^{-1} \mathrm{FM}$ in normal years (evaluation region 3 , not shown).

Temperate zone woodland:

In Olson et al. (2001) many woodland stands over Europe are found in the class B data set. For mixed woodland stands in Romania values between 323 to $1026 \mathrm{gC} \mathrm{m}^{-2} \mathrm{a}^{-1} \mathrm{FM}$ are reported, and in French woodland stands values between 616 to $817 \mathrm{gC} \mathrm{m}^{-2} \mathrm{a}^{-1}$ FM. German woodland show values between 539 to $912 \mathrm{gC} \mathrm{m}^{-2} \mathrm{a}^{-1} \mathrm{FM}, 893$ to $1349 \mathrm{gC} \mathrm{m}^{-2} \mathrm{a}^{-1}$ FM and 677 to $1235 \mathrm{gC} \mathrm{m}^{-2} \mathrm{a}^{-1} \mathrm{FM}$. A woodland stand in the Netherlands shows values of 816 to $1007 \mathrm{gC} \mathrm{m}^{-2} \mathrm{a}^{-1} \mathrm{FM}$. In the United Kingdom values of 154 to $1653 \mathrm{gC} \mathrm{m}^{-2} \mathrm{a}^{-1} \mathrm{FM}$ with a mean value of $603 \mathrm{gC} \mathrm{m}^{-2} \mathrm{a}^{-1} \mathrm{FM}$ are reported in more than 40 mixed woodland stands for 1956 and 1959. Esser (1998) reports NPP values for woodland stands in Germany, which range from 429 to $2975 \mathrm{gC} \mathrm{m}^{-2} \mathrm{a}^{-1} \mathrm{FM}$ with a mean value of $1700 \mathrm{gC} \mathrm{m}^{-2} \mathrm{a}^{-1} \mathrm{FM}$. For stands in Belgium they report numbers from 665 to $1743 \mathrm{gC} \mathrm{m}^{-2} \mathrm{a}^{-1}$ FM with a mean of $1130 \mathrm{gC} \mathrm{m}^{-2} \mathrm{a}^{-1} \mathrm{FM}$.

Taking into account all given numbers, the total NPP for temperate zone woodlands ranges between 154 to $2975 \mathrm{gC} \mathrm{m}^{-2} \mathrm{a}^{-1}$ FM. Simulated NPP values of the humid temperate climate zone (evaluation regions 3 to 6 , not shown) for deciduous and needleleaf trees range between 1000 and $2400 \mathrm{gC} \mathrm{m}^{-2} \mathrm{a}^{-1} \mathrm{FM}$.

Boreal zone woodland:

NPP values for boreal zone woodland stands are reported in the class A data set of Olson et al. (2001). The values range from 86 to $931 \mathrm{gC} \mathrm{m}^{-2} \mathrm{a}^{-1} \mathrm{FM}$ with a mean value of $459 \mathrm{gC} \mathrm{m}^{-2} \mathrm{a}^{-1} \mathrm{FM}$. Esser (1998) reports 899 to $1824 \mathrm{gC} \mathrm{m}^{-2} \mathrm{a}^{-1} \mathrm{FM}$ with a mean value of $1300 \mathrm{gC} \mathrm{m}^{-2} \mathrm{a}^{-1} \mathrm{FM}$ for woodlands in Sweden and a range from 321 to $1304 \mathrm{gC} \mathrm{m}^{-2} \mathrm{a}^{-1} \mathrm{FM}$ with a mean value of $637 \mathrm{gC} \mathrm{m}^{-2} \mathrm{a}^{-1} \mathrm{FM}$ for woodland stands in Finland. Evaluation regions 12-15 define boreal climate types. The simulated NPP values for the woodlands in 


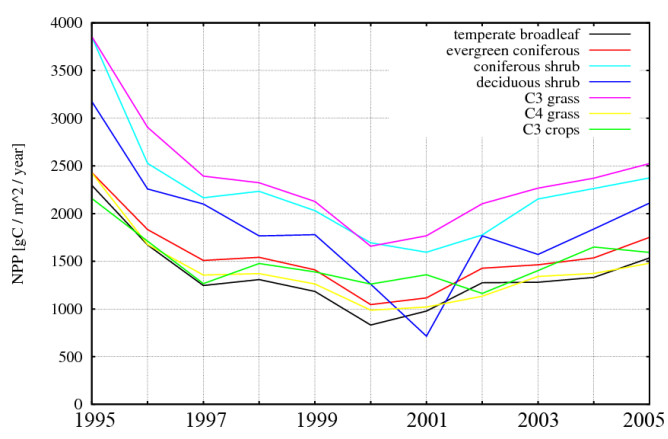

(a) Region 8 (Csa climate)

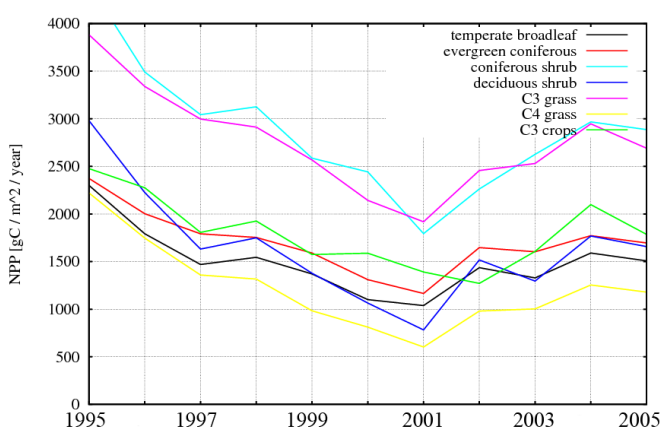

(b) Region 8 (Csb climate)

Figure 13. Net primary productivity $\left[\mathrm{gC} \mathrm{m}^{-2} \mathrm{a}^{-1} \mathrm{FM}\right]$ variations in evaluation region 8 in the period 1995 to 2005 .

these regions ranges between 700 and $1500 \mathrm{gC} \mathrm{m}^{-2} \mathrm{a}^{-1}$ FM (regions 12-15, not shown).

\section{Boreal zone grassland and tundra:}

NPP values for boreal zone grassland and tundra for many stands are reported in Esser (1998) and range from 171 to $826 \mathrm{gC} \mathrm{m}^{-2} \mathrm{a}^{-1} \mathrm{FM}$ with a mean of $533 \mathrm{gC} \mathrm{m}^{-2} \mathrm{a}^{-1}$ FM. Olson et al. (2001) report values from 210 to $343 \mathrm{gC} \mathrm{m}^{-2} \mathrm{a}^{-1} \mathrm{FM}$ for boreal grassland locations. The simulated values for grass PFTs in the boreal evaluation regions (regions 12-15, not shown) show values between 1200 to $2200 \mathrm{gC} \mathrm{m}^{-2} \mathrm{a}^{-1} \mathrm{FM}$.

\section{Discussion}

We implemented a new land surface scheme into the regional climate model REMO and advanced the representation of vegetation and associated processes. These changes lead to the differences in the simulated climate as described in Sects. 5.1.4 and 5.1.5. We discuss the main findings here.

The most distinct changes for the high northern latitudes are changes due to forest cover and the associated snowmasking mechanism. These effects lead to an increase in near-surface temperature in REMO-iMOVE (Sect. 5.1.4). Despite the small radiative input in winter in these regions, we see a significant change in temperature, which highlights the importance of surface albedo in these regions. The fact that the cold bias in the described part of the domain is only reduced but still remains in REMO-iMOVE, even with decreased intensity, leads to the conclusion that other mechanisms apart from the surface variables contribute to the bias. Since it is not within the scope of this experiment, this feature is not further examined here.

Another important effect is the intensification of the warm bias in the Balkans region in late summer. This can be clearly attributed to the changes in the vegetation cover properties, represented by LAI and VGR. The vegetation type in these regions mainly consists of crop PFTs (C3 and C4). In contrast to the old model version, the newly introduced crop phenology in REMO-iMOVE is able to react dynamically to the atmospheric signal (as described in Sect. 2.1.2). Hence, the crops are harvested when the growing degree threshold, depending on temperature, is reached, and no longer at a fixed date. This phenological scheme for crops is able to simulate the LAI in very good agreement to observed LAI values (Sect. 5.1.5), which is an improvement compared to REMO2009. The dynamic harvest of crops leads to a distinct drop in LAI and VGR mainly in August and September. This early and strong decrease of vegetation density reduces the latent heat flux and thus the near-surface evaporative cooling. This leads to distinctly increased near-surface temperatures.

Another feedback related to crop phenology is the reduced moisture recycling due to less near-surface and atmospheric moisture availability. Less atmospheric moisture leads locally to a decrease in precipitation. The moisture recycling feedback with decreased precipitation is mostly visible in the Hungarian Basin and the Balkans in July and August, when the energetic driver, the insolation, reaches its maximum values.

As described in Sect. 2.1.2, the parameterization of bare soil evaporation was improved. This leads to a further increase of surface temperatures in the stated regions. This static method improves some of the shortcomings of REMO2009, but it is not able to capture realistic soil moisture dynamics like a multi-layer soil water scheme.

The interactive coupling of REMO with the new vegetation scheme captures dynamic changes of vegetation properties like the annual cycle of LAI and photosynthetic activity due to atmospheric and soil conditions. Section 5.2.1 shows that REMO-iMOVE is able to reproduce the observed annual cycle of vegetation in most evaluated regions. Shortcomings still exist in some semi-arid and continental climate regions. The observed LAI values in the evaluation regions 9 and 10 do not exceed the limit of 1 (Fig. 10). The simulated values show a maximum of nearly 2.5 . The plant growth in these regions is mainly limited by water availability. Figure 14 shows the soil water dynamics for the evaluation regions 9 

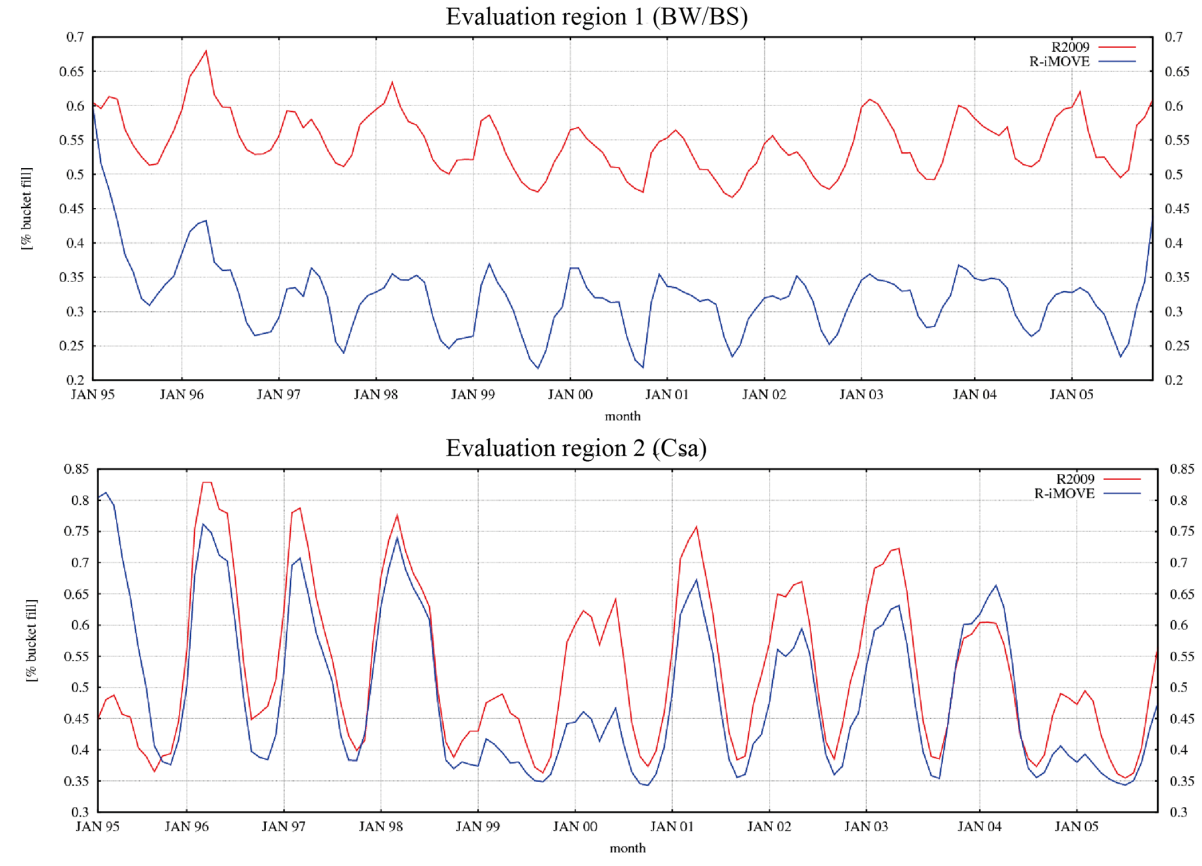

Figure 14. Annual courses of soil moisture in two evaluation regions of REMO-iMOVE and REMO2009 (compare Fig. 3).

and 10. In the model, a value below $35 \%$ of the bucket fill means that the wilting point in the soil is reached and no more water is available to plants. If the value is above $35 \%$, water is available for plant growth. It is clearly seen that the bucket fill never drops below $35 \%$ in region 9 , even if it is located partly in semi-arid environment. In evaluation region 10 , we would also expect strong plant water stress in summer due to the continental climate characteristics. But the bucket fill always exceeds $35 \%$, meaning that water is available for plant growth. As stated earlier, the bucket soil water scheme of REMO is not able to represent vertical soil moisture dynamics. This would be needed for a near-realistic image of plant growth in these regions. But with the simple bucket scheme, we overestimate LAI values. Another factor for overestimated LAI magnitudes is the model bias in summer precipitation, which can be up to 40 to $60 \%$ in the referred regions.

REMO-iMOVE now implies a new source of climate variability, since the vegetation cover interactively adjusts to atmospheric and soil moisture conditions. For studies on future climate change this is of high importance, as plants are now able to adjust the growing conditions to changing climate conditions. The LAI courses in Fig. 10 and the NPP time series in Figs. 12 and 13 clearly show the influence of variations in simulated weather characteristics on vegetation growth and productivity.

One newly introduced model feature in REMO-iMOVE is the net primary productivity of vegetation (NPP). We discuss the stated numbers and findings of Sect. 5.2.2 in more detail here. In the model, the productivity in arid and semi-arid regions is mainly limited by the soil moisture availability. The strong dependence of plant productivity on soil water is given in an extreme case in the first year of the model run, where the soil water spin-up took place. Figure 11 shows the modelled NPP values and Fig. 14 shows the soil moisture for evaluation region 1 for the BW/BS climate. It is evident for region 1 in the first year of spin-up, that the productivity values are high, because water is available in the soil. After the soil spin-up the productivity values drop, since only in very few months in some single years is the soil water in excess of $35 \%$ of the bucket fill and therefore available for the plants. The comparison to NPP observations indicate that the simulated values are reasonable and the dependence on soil water is well represented. We conclude that with this new parameter it is possible to simulate plant productivity under changing climate conditions and its feedback on climate can be studied in transient climate change projections.

The productivity of Mediterranean grassland environments is also limited mostly by soil water which is illustrated by the observations of Roy et al. (2001). The model is able to follow this feature, which can be seen in the Csa climate of evaluation region 2 (Fig. 12), where in exceptionally dry years (1999, 2000, 2005, see soil moisture courses in Fig. 14) the productivity drops drastically. The overall numbers show a good comparison to the spread in the observations.

The NPP of Mediterranean shrub- and woodland associations in the model ranges in the upper limit of the observations or beyond. Not only water, but also nutrient limitation and stand age, are important factors to plant growth in this 
climatic regime. Since neither nutrient limitation nor stand age is modelled, the model simulates such high NPP values.

Plant productivity of temperate and boreal zone woodland is represented generally well in the model. It has some problems to meet the lower limit, but matches the upper limit quite well. Also the productivity of boreal zone grassland is overestimated in the model. The tendency towards too high productivity in these climatic regions is likely connected to the fact that nutrient limitation or pests are not modelled in REMO-iMOVE. The reason here may be either the unsatisfying nutrient limitation or the parameter sets in the photosynthesis scheme controlling the carboxylation and maximum electron transport rate (Bonan et al., 2011).

\section{Conclusions}

In this study, we coupled the RCM REMO with vegetation modules of the MPI-ESM land surface scheme JSBACH, to the regional climate system model REMO-iMOVE. We introduced the concept of plant functional types. We developed a method to derive the spatial fraction of PFTs for each model grid cell from the geographic distribution of GLC2000 vegetation types. For mixed PFTs, we further combine this allocation method with the Holdridge ecosystem classification scheme. Up to 16 PFT types can co-exist in a single grid cell. They directly represent specific biophysiological characteristics and functionalities, which interact dynamically with atmospheric and soil conditions. This introduces new dynamic feedbacks between land and atmosphere, which can be studied under changing climate conditions. The net primary productivity is an important parameter for carbon cycle studies. The conduction of carbon cycle studies is now possible on detailed resolution with a regional climate model.

We analysed the results of climate simulation for Europe in $0.44^{\circ}$ resolution, forced by ERA-Interim boundaries for 1995 to 2005, conducted with both model versions. The simulations show that the new developed model version REMOiMOVE is able to simulate the European climate with the same quality as REMO2009. The occurring differences reveal the influence of the surface schemes on the simulated climate, which can be distinct in some regions. The main reasons for the different behaviour of the two model versions are the different temporal dynamics of vegetation cover and density (VGR and LAI) and changes in the soil scheme. These parameters influence the surface heat and moisture fluxes and lead to changes in the simulated near surface climate.

We could further show that the simulated inter-annual variability in plant phenology, as well as the simulated NPP values, are in the range of observations for most European regions. Shortcomings occur in regions where the simple soil moisture scheme is not able to capture soil hydrological dynamics influencing plant growth. The direct comparison of the model versions reveals the qualitative gain in modelling LAI dynamics with REMO-iMOVE.
Apart from the model advances realized here, major efforts should be put into the development of a multi-layer soil hydrology scheme. This will improve the simulation of productivity of soil water-limited PFTs, but also the underestimation of bare soil evaporation in subtropical and dry central European regions. Also the implementation of carbon pool dynamics and spatial vegetation shifts into REMOiMOVE will first require an advanced soil water scheme, as multi vertical water layers are needed for representing root water competition. The dynamic vegetation scheme of JSBACH strongly depends on plant productivity. Solely soil water-limited PFTs would then be limited in growth and the PFT distribution would show realistic dynamics. In the current REMO-iMOVE version, these PFTs would have strong advantages over all other PFTs, therefore we did not include the dynamic vegetation in this model version.

Acknowledgements. The work has been carried out at the Max Planck Institute for Meteorology and the Climate Service Center in Hamburg and was funded by the EU FP 7 project ACQWA. The authors posthumously thank the patient character of Ralph Podzun, the former chief developer of REMO, for his support in illustrating the technical details of the model REMO. Further we thank C. H. Reick, T. Raddatz and R. Schnur for their support with the JSBACH model.

The service charges for this open access publication have been covered by the Max Planck Society.

Edited by: M.-H. Lo

\section{References}

Avissar, R. and Pielke, R.: The impact of plant stomatal control on mesoscale atmospheric circulations, Mon. Weather Rev., 117, 213-315, 1991.

Baret, F., Hagolle, O., Geiger, B., Bicheron, P., Miras, B., Huc, M., Berthelot, B., F., N., Weiss, M., Samain, O., Roujean, J., and Leroy, M.: LAI, FAPAR, and FCover CYCLOPES global products derived from Vegetation. Part 1: principles of the algorithm, Remote Sens. Environ., 110, 305-316, 2007.

Bartholome, E. and Belward, A.: GLC2000: A new approach to global land cover mapping from Earth observation data, Int. J. Remote Sens., 26-9, 1959-1977, 2005.

Betts, R., Cox, P., Lee, S., and Woodward, F.: Contrasting physiological and structural vegetation feedbacks in climate change simulations, Nature, 387, 796-799, 1997.

Bonan, G.: Ecological Climatology, Cambridge University Press, Cambridge, United Kingdom and New York, NY, USA, 2002.

Bonan, G., Oleson, K., Levis, S., Jung, M., Reichstein, M., Lawrence, D., and Swenson, S.: Improving canopy processes in the Community Land Model version 4 (CLM4) using global flux fields empirically inferred from FLUXNET data, J. Geophys. Res., 116, 1-22, 2011.

Brovkin, V., Boysen, L., Raddatz, T., Gayler, V., Loew, A., and Claussen, M.: Evaluation of vegetation cover and land-surface 
albedo in MPI-ESM CMIP5 simulations, J. Adv. Model. Earth Syst., 5, 48-57, 2013.

Cao, L., Bala, G., Caldeira, K., Nemani, R., and Ban-Weiss, G.: Importance of carbon dioxide physiological forcing to future climate change, Proc. Natl. Aca. Soc., 107, 9513-9518, 2010.

Collatz, G., Ribas-Carbo, M., and Berry, J.: A coupled photosynthesis-stomatal conductance model for leaves of $\mathrm{C} 4$ plants, J. Plant Physiol., 19, 519-538, 1992.

Davin, E., Stoekli, R., Jaeger, E. B., Levis, S., and Seneviratne, S.: Cosmo-CLM $^{2}$ : a new version of the COSMO-CLM model coupled to the Community Land Model, Clim. Dynam., 37, 18891907, doi:10.1007/s00382-011-1019-z, 2011.

Dickinson: Land surface processes and climate-surface albedos and energy balance, Adv. Geophys., 25, 305-353 (ISBN 0-12018825-2), 1983.

Esser, G.: NPP Multi-Biome: Global Osnabruck Data, 1937-1981, Data set, ORNL/TM-2001/196, Oak Ridge National Laboratory, Oak Ridge, Tennessee USA, 1998.

FAO/IIASA/ISRIC/ISSCAC/JRC: Harmonized World Soil Database (version 1.1), FAO, Rome, Italy and IIASA, Laxenburg, Austria, 2009.

Farquhar, G., von Caemmerer, S., and Berry, J.: A Biochemical Model of Photosynthetic $\mathrm{CO}_{2}$ Assimilation in Leaves of $\mathrm{C}_{3}$ Species, Planta, 149, 78-80, 1980.

Garrigues, S., Lacaze, R., Baret, F., Morisette, J. T., Weiss, M., Nickeson, J. E., Fernandes, R., Plummer, S., Shabanov, N. V., Myneni, R. B., Knyazikhin, Y., and Yang, W.: Validation and intercomparison of global Leaf Area Index products derived from remote sensing data. J. Geophys. Res., 113, G02028, doi:10.1029/2007JG000635, 2008.

Giorgi, F.: Regional climate modeling: status and perspectives, J. Phys., 139, 101-118, 2006.

Hagemann, S.: An Improved Land Surface Parameter Dataset for Global and Regional Climate Models, Max-Planck-Institute for Meteorology, Hamburg, Germany, Report 336, 1-21, (ISSN 0937-1060), 2002.

Hagemann, S., Botzet, M., Duemenil, L., and Machenhauer, M.: Derivation of global $\mathrm{gcm}$ boundary conditions from $1 \mathrm{~km}$ land use satellite data. Max-Planck-Institute for Meteorology, Hamburg, Germany, 289, 1999.

Haylock, M., Hofstra, T., Tank, A., Klok, E., Jones, P., and New, M.: A European daily high-resolution gridded data set of surface temperature and precipitation for 1950-2006, J. Geophys. Res., 113, D20119, doi:10.1029/2008JD010201, 2008.

Holdridge, L.: Life Zone Ecology, Tropical Science Center, San Jose, Costa Rica, 1964.

Jacob, D.: A note 825 to the simulation of the annual and interannual variability of the water budget over the baltic sea drainage basin, Meteorol. Atmos. Phys., 77, 61-73, 2001.

Jacob, D. and Podzun, R.: Sensitivity studies with the regional climate model remo, Meteorol. Atmos. Phys., 63, 119-129, 1997.

Jeong, S., Ho, C., Kim, K., Kim, J., Jeong, J., and Park, T.: Potential impact of vegetation feedback on European heat waves in a $2 \mathrm{x}$ $\mathrm{CO}_{2}$ climate, Climate Change, 99, 625-635, 2010.

Jung, M., Reichstein, M., Margolis, H., Cescatti, A., Richardson, A., Arain, M., Arneth, A., Bernhofer, C., Bonal, D., Chen, J., Gianelle, D., Gobron, N., Kiely, G., Kutsch, W., Lasslop, G., Law, B., Lindroth, A., Merbold, L., Montagnani, L., Moors, E., Papale, D., Sottocornola, M., Vaccari, F., and Williams, C.: Global pat- terns of land-atmosphere fluxes of carbon dioxide, latent heat, and sensible heat derived from eddy covariance, satellite, and meteorological observations, J. Geophys. Res. Biogeosci., 116, G00J07, doi:10.1029/2010JG001566, 2011.

Knorr, W.: Satellite remote sensing and modeling of the global $\mathrm{CO}_{2}$ exchange of land vegetation: A synthesis study, Examensarbeit Nr. 49, 1998.

Koeppen, W.: Versuch einer Klassifikation der Klimate, vorzugsweise nach ihren Beziehungen zur Pflanzenwelt, Geographische Z., 6, 593-611, 1900.

Kotlarski, S.: A Subgrid Glacier Parametrisation for Use in Regional Climate Modelling, Max-Planck-Institute for Meteorology: Reports on Earth System Science, Hamburg, 2007.

Lu, L., Pielke, R., Liston, G., Parton, W., Ojima, D., and Hartman, M.: Implementation of a two-way interactive atmospheric and ecological model and its application to the central United States, J. Climate, 14, 900-919, 2001.

Majewski, D.: The Europa-Modell of the Deutscher Wetterdienst, Proceedings of the ECMWF Seminar on Numerical Methods in Atmospheric Models, Reading, UK, 9-13, 147-191, 1991.

Marsland, S., Haak, H., Jungclaus, J., Latif, M., and Roeske, F.: The Max Planck Institute global ocean/sea-ice model with orthogonal curvilinear coordinates, Ocean. Modell., 5, 91-127, 2003.

Mitchell, T. and Jones, P.: An improved method of constructing a database of monthly climate observations and associated highresolution grids, Int. J. Climatol., 25, 693-712, 2005.

Muller, E. and Decamps, H.: Modeling soil moisture-reflectance, Remote Sens. Environ., 76, 173-180, 2001.

Murray, M., Cannel, M., and Smith, R.: Date of budburst of fifteen tree species in Britain following climate warming, J. Appl. Ecol., 26, 693-700, 1989.

Olson, J.: Global ecosystem framework definitions, USGS EROS Data Center Internal Report, Sioux Falls, SD, 1994.

Olson, R., Johnson, K., Zheng, D., and Scurlock, J.: Global and Regional Ecosystem Modeling: Databases of Model Drivers and Validation Measurements, ORNL/TM-2001/196. Oak Ridge National Laboratory, Oak Ridge, Tennessee USA, 2001.

Peterson, J., Robinson, B., and Beck, R.: Predictability of Change in Soil Reflectance on Wetting, Machine Processing of Remotely Sensed Data Symposium, Laboratory for Applications of Remote Sensing: LARS Technical Reports, Purdue Libraries, 062479, 264-273, 1979.

Pfeiffer, S.: Modeling cold cloud processes with the regional climate model REMO, Max-Planck- Institute for Meteorology, Reports on Earth System Science, Hamburg, 2006.

Rechid, D. and Jacob, D.: Influence of monthly varying vegetation on the simulated climate in Europe, Meteorol. Z., 15, 99-116, 2006.

Rechid, D., Raddatz, T., and Jacob, D.: Parameterization of snowfree land surface albedo as a function of vegetation phenology based on MODIS data and applied in climate modelling, Theor. Appl. Climatol., 95, 245-255, 2009.

Reick, C., Raddatz, T., Brovkin, V., and Gayler, V.: The representation of natural and anthropogenic land cover change in MPIESM, J. Adv. Model. Earth Syst., 5, 459-482, 2013.

Roeckner, E., Arpe, K., Bengtsson, L., Christoph, M., Claussen, M., Duemenil, L., Esch, M., Giorgetta, M., Schlese, U., and Schulzweida, U.: The Atmospheric General Circulation Model Echam-4: Model Description and Simulation of the Present Day 
Climate, Max-Planck-Institute for Meteorology, Report No. 218, 2000.

Roeckner, E., Baeuml, G., Bonaventura, L., Brokopf, R., Esch, M., Giorgetta, M., Hagemann, S., Kirchner, I., Kornblueh, L., Manzini, E., Rhodin, A., Schlese, U., Schulzweida, U., and Tompkins, A.: The atmospheric general circulation model ECHAM 5. PART I: Model description, Max-Planck-Institute for Meteorology, Report No. 349, 2003.

Roy, J., Saugier, B., and Mooney, H.: Terrestrial Global Productivity, Academic Press, New York, 2001.

Rudolf, B. and Schneider, U.: Calculation of Gridded Precipitation Data for the for the Global Land-Surface using in-situ Gauge Observations, Proceedings of the 2nd Workshop of the International Precipitation Working Group IPWP, Montery October, 2004.

Schultz, J.: Die Oekozonen der Erde, UTB, Stuttgart, 2002.

Sellers, P.: Canopy reflectance, photosynthesis and transpiration., Int. J. Remote Sens., 6, 1335-1375, 1985.

Shipley, B. and Vu, T.: Dry matter content as a measure of dry matter concentration in plants and their parts, New Phytologist, 153, 359-364, 2002.

Simmons, A., Uppala, S., Dee, D., and Koobayashi, S.: ERAInterim: New ECMWF reanalysis products from 1989 onwards, ECMWF Newsletter, 110, 26-35, 2006.

Sitch, S., Smith, B., Prentice, I., Arneth, A., Bondeau, A., Cramer, W., Kaplan, J., Levis, S., Lucht, W., Sykes, M., Thonicke, K., and Venevsky, S.: Evaluation of ecosystem dynamics, plant geography and terrestrial carbon cycling in the LPJ Dynamic Vegetation Model, Glob. Change Biol., 9, 161-185, 2003.
Steiner, A., Pal, J., Rauscher, S., Bell, J., Diffenbaugh, N., Boone, A., Sloan, L., and Giorgi, F.: Land surface coupling in regional climate simulations of the West African monsoon, Clim. Dynam., 33, 869-892, 2009.

Stevens, B., Giorgetta, M., Esch, M., Mauritsen, T., Crueger, T., Rast, S., Salzmann, M., Schmidt, H., Bader, J., Block, K., Brokopf, R., Fast, I., Kinne, S., Kornblueh, L., Lohmann, U., Pincus, R., Reichler, T., and Roeckner, E.: The atmospheric component of the MPI-M earth system model: ECHAM6, JAMES, 5, 1-27 doi:10.1002/jame.20015, 2013.

Taylor, K., Stouffer, R., and Meehl, G.: An Overview of CMIP5 and the Experiment Design, Bull. Amer. Meteor. Soc., 93, 485-498, 2004.

Teichmann, C.: Climate and Air Pollution Modelling in South America with Focus on Megacities, Max-Planck-Institute for Meteorology: Reports on Earth System Science, Hamburg, 2010.

Tsvetsinskaya, E., Schaaf, C., Gao, F., Strahler, A., Dickinson, R., Zeng, X., and Lucht, W.: Relating MODIS-derived surface albedo to soils and rock types over Northern Africa and the Arabian peninsula, Geophys. Res. Lett., 29, 67-1:67-4, 2011.

Warrilow, D., Sangster, A., and Slingo, A.: Modelling of land surface processes and their influence on European climate, Meteorological Office Technical Note DCTN 38, Backnell, UK, 2007.

Weiss, M., Baret, F., Garrigues, S., and Lacaaze, R.: LAI and fAPAR CYCLOPES global products derived from VEGETATION, Part 2: validation and comparison with MODIS collection 4 products, Remote Sens. Environ., 110, 317-331, doi:10.1016.j.rse.2007.03.001, 2007.

Zobler, L.: A world soil file for global climate modelling, Technical Memorandum 87802, NASA, 1986. 